Portland State University

PDXScholar

7-3-1995

\title{
Dialogue and Critical Thinking in Personal Action
}

Amanda Elizabeth Feller

Portland State University

Follow this and additional works at: https://pdxscholar.library.pdx.edu/open_access_etds

Part of the Speech and Rhetorical Studies Commons

Let us know how access to this document benefits you.

\section{Recommended Citation}

Feller, Amanda Elizabeth, "Dialogue and Critical Thinking in Personal Action" (1995). Dissertations and Theses. Paper 4962.

https://doi.org/10.15760/etd.6838

This Thesis is brought to you for free and open access. It has been accepted for inclusion in Dissertations and Theses by an authorized administrator of PDXScholar. Please contact us if we can make this document more accessible: pdxscholar@pdx.edu. 


\section{THESIS APPROVAL}

The abstract and thesis of Amanda Elizabeth Feller for the Master of Science in Speech Communication were presented July 3, 1995, and accepted by the thesis committee and the department.

COMMITTEE APPROVALS:
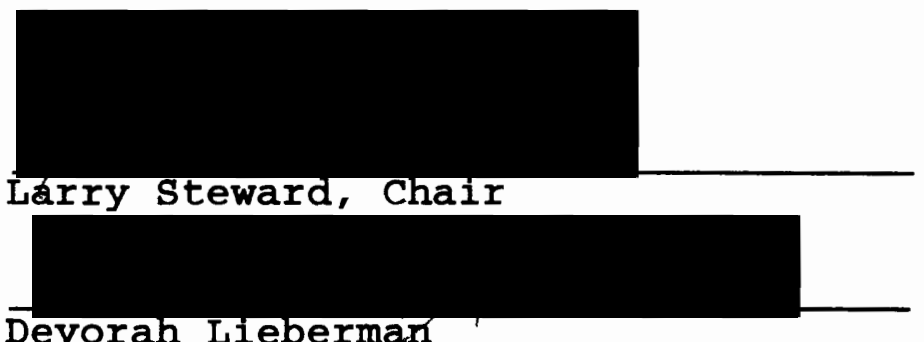

Devorah Lieberman

DEPARTMENT APPROVAL:

Stephen A. Kosokfoly, Chair

Department of speech Communication

ACCEPTED FOR PORTLAND STATE UNIVERSITY BY THE LIBRARY

by one27 Lapeq5 


\section{ABSTRACT}

An abstract of the thesis of Amanda Elizabeth Feller for the Master of Science in Speech Communication presented July 3, 1995.

Title: Dialogue and Critical Thinking in Personal Action

A common criticism of U.S. citizens today, whether as voters or students or workers, is that they are "lazy and apathetic". It is important to explore the validity of this criticism. This thesis begins with the premise that there are two prerequisites for citizenship in a democracy:

that citizens be willing to participate and (2) that citizens are able to participate.

The purpose of this research is to examine a particular set of perspectives regarding social conditions which consistently impact the two aforementioned prerequisites. This examination addresses social conditions that undermine a person's ability to participate meaningfully and it addresses perspectives on alternative social conditions which support personal action.

Included in this set of perspectives are relevant concepts and ideas derived from Socrates, John Locke, Karl Marx, Anthony Giddens, and Michael Lerner. These prominent 
thinkers provide likely, but not exclusive examples of how certain themes commonly emerge regarding social conditions and their relationship to communication. Each of these sources, in different ways and to different degrees, demonstrates how social conditions commonly encourage ideology that can undermine personal action. Additionally, each theorist indicates the need for dialogue and critical thinking to penetrate these social conditions and ideologies, thus providing the keys to encouraging personal action.

Once established, the potential for dialogue and critical thinking is discussed with regard to several important social arenas and systems of American culture: mass media, education, the workplace, and government. The true test of whether or not Americans are willing to participate depends upon the nature and extent of their ability to participate. As the promotion of dialogue and critical thinking is necessary to assure the second, an exploration of these capacities is necessary to begin assessing the first. 
AMANDA ELIZABETH FELLER

A thesis submitted in partial fulfillment of the requirements for the degree of

\author{
MASTER OF SCIENCE \\ in \\ SPEECH COMMUNICATION
}

Portland State University

1995 


\section{ACKNOWLEDGMENTS}

For their patience, insight, assistance, and support in a time of need, I would like to acknowledge the contributions of the following people:

Randall Blake Baker, Larry steward, Devorah Lieberman, Byron Haines, Douglas Clayton Ehrmantraut, Peter Ehrenhaus, Leslie T. Good, L. David Ritchie, steve Kosokoff, Debbie Gabbert, Pat Hamilton, Suzanne Evers, Ken Fox, Gisele Tierney, Susan Poulsen, and the teaching assistants of the speech Communication Department. 


\section{TABLE OF CONTENTS}

CHAPTER I: INTRODUCTION.................. Page 1

CHAPTER II: THEORETICAL ORIGINS.............Page 10 Socrates

John Locke

Karl Marx

Anthony Giddens

Michael Lerner

CHAPTER III: synThesis...................Page 49

CHAPTER IV: DISCUSSION...................Page 62

Implications for Mass Media

Implications for Educational systems

Implications for the Organization of Work

Implications for Governmental systems

CHAPTER V: THESIS SUMMARY................Page 146

REFERENCES CITED........................Page 152 


\section{CHAPTER I: INTRODUCTION}

Democracy is a process for transforming individual wishes into social action. Democratic governments operate by sets of formal rules, which (in theory) guide and protect the process of democracy at the social level. Democracy is based on several traditional values, one of which is key: individual participation (Zeigler, 1993). More specifically, it is an assumption of any democratic process that the most desirable impetus for social change is the input of individuals within the citizenry. This assumed value is dependent upon two vital criteria for success:

(1) that the citizenry is able to participate

(2) that the citizenry is willing to participate

A democratic government, as an institution at least nominally aimed at protecting democratic process, must be concerned with encouraging the circumstances that fulfill these two important criteria. Traditionally, democratic governments fulfill these requirements through guaranteed access to the means of public discourse, and through guaranteed access to the mechanisms for decision-making at the governmental level. In other words, individuals can communicate with the citizenry, and can participate in the process of government itself.

The assumption implicit in traditional democratic 
governments is that if people are made able to participate, they will naturally be willing to particlpate. This is because participation is assumed to be in the individual's self-interest.

There is however, growing evidence that United states citizens are choosing not to participate, as is reflected in low voter turn-out and negativity about personal political influence (Flanigan \& Zingale, 1987; Patterson, 1993). While such evidence is arguably inconclusive (there are many forms of participation,) it raises questions that strike at the heart of democratic survival. This powerful basis for concern demands to be addressed--not only through analysis of participation habits, but also through research aimed at discovering the factors related to individual participation choices.

Communication is inextricably tied to democratic survival through the means of public discourse (Bohman, 1990; Dewey, 1966). Individuals must have the opportunity to engage each other at the public level; such engagement must be meaningful enough to the democratic process that citizens believe individual participation is effective. Without such public dialogue, democracy lacks the diversity of views and the critical focus necessary to fulfill democratic process (Zeigler, 1993). 
Embedded in the preceding views of society and government is a long history of Western thought that reaches from Socrates to John Locke and beyond. Each of these perspectives shares common attributes and assumptions that, when extracted from their particular backgrounds and applied as common principles, reveal a host of challenges for contemporary researchers and citizens alike.

In this research, it is argued that there is a cluster of important concepts and theories that draw vital attention to the role of communication in our contemporary democracy and to the nature of individual participation. A healthy democracy depends, in theory, upon the existence of three interrelated social activities: dialogue, critical thinking, and personal action. There are common social conditions, even in a democracy, that tend to undermine the practice of these core activities. In this work, I will examine five prominent Western thinkers to demonstrate that these three activities (dialogue, critical thinking, and personal action), and the common barriers against them, are theoretically and historically recurring in Western thought. Through this examination, I will also show that there is a common answer to the challengers that face democracy. That answer lies in confronting social isolation through specific forms of communication. 
Chapter II of this research will sequentially examine the work and ideas of Socrates, John Locke, Karl Marx, Anthony Giddens, and Michael Lerner. This examination will center upon the conceptual relationship that each work has with dialogue, critical thinking, and personal action. Chapter III will offer a synthesis of these philosophers, as together they provide a meaningful composite. This synthesis will center upon how specific forms of communication can overcome the barriers to personal action in a democratic society. Chapter IV will discuss the implications this synthesis has for several arenas prominent in American culture including mass media, education, the workplace, and government.

\section{Research Rationale}

The obvious question arises, "why these five individuals?", specifically, "why five white male Europeandescended thinkersp" The first and most important answer is that this research should indicate the common, even mainstream existence of the relationships of concepts discussed. There are many individuals living and dead, male and female, Caucasian and people of other colors, who discuss these same ideas - - and really that is part of the 
point - these ideas are truly common. However, it is particularly important that this research be seen not as the new and adventurous invention of social theory, but rather as the teasing out and synthesis of values and convictions that Western civilization has always had. To conduct this research with reference to contemporary, progressives or even "alternative" thinkers would deviate from or even undermine the point that these relationships are not merely common, but also classical. In the everyday world, whether or not we act on them constitutes what is progressive, alternative, and radical. The fact that these relationships are recurring and ever-present in history is indicative of something that truly demands attention.

Second these particular five thinkers resonate with an expansion of ideas that help define the concept relationships of this research. There is a common theme among them, whether directed at the personal or the public scale. This theme is suggestive of the potential of dialogue, critical thinking, and personal action as well as being indicative of the barriers against them. Socrates, Locke, Marx, Giddens, and Lerner standout as holding within them pieces central to this relevant and significant theme. Finally, it is useful to provide a brief biographical sketch of who these individuals are and to acknowledge that 
they indeed have their differences.

Socrates was a teacher and, what we would think of today as a politician, during the fifth century B.C He had a major influence on Athens in his day and upon the whole of Western philosophy (Golden,et.al., 1989). Socrates is known to us only through the transcriptions of his instructions -. he believed in dialogue as a means for discovery, instruction, and fulfillment of human aspirations. Ultimately Socrates was given the choice of exile or death by the Athenian Aristocracy. His philosophy of dialogue and the discoveries to which it led were perhaps too revealing for the comfort of the elite.

John Locke is considered to be one of the most influential English philosophers. His background, education, and writings spanned topics from science to human nature to governmental systems. During the 1600 's he responded in his writings to the ideas of Galileo and Descartes alike and he often kept company with Isaac Newton (Flew, 1984). Many of his ideas served as a foundation for early American government. Locke is described as an empiricist that sought out knowledge and reflected upon the power of language to give shape to ideas. His ideas remain as a reference point in many discussions about human nature, government, and methods by which both are examined. 
Karl Marx was a social theorist, philosopher, and political scientist during the 1800 's. His ideas are found at the center of many debates regarding the economic systems of communism, socialism, and capitalism. The way in which he approached his ideas is also at the center of debate regarding methods of understanding and examining a variety of perspectives. More familiar to us of course, is the transformation of Marx's ideas into Marxism - a loose association at best -- and into the principles that guided governments such as that of modern China and the former Soviet Union.

Lesser known are the more contemporary thinkers, Anthony Giddens and Michael Lerner. Much of Giddens' work has been to deconstruct and examine the work of many social theorists and philosophers. His work has been guided by an interest in the static and fixed conception of the world presented by these many ideas. His insights have taken their place in a new series of debates regarding the world as a set of systems rather than as a set of structures. It can be said of Giddens that he has given new life and meaning to the social theories that have preceded his own. Michael Lerner is another individual who has crossed and consequently integrated several fields of social science including psychology and philosophy. His work has been in 
the making and published throughout the 20 th century. As a contemporary, his work has found its way into the mainstream as well as into the professional and academic worlds.

Lerner often takes an approach of integrating not only many fields, but also integrating theory and practice. As a result his ideas act as both a philosophy and as a working, living model. While his works discuss a variety of topics, Lerner has a keen interest in people and their ability (as well as their willingness) to find fulfillment, strength, and cohesion.

These biographical sketches portray individuals who live or have lived different lives and in different environments. Undoubtedly, if they could all be assembled together in one room the discussion and debate that ensued would be something to behold. Perhaps, Marx would tell Socrates that he must takes his method to the masses. Perhaps, Locke would insist to Marx that should people want out of capitalism and into socialism, they would find a way out. Perhaps, Giddens would carefully explain to them all that they are missing the point entirely and that they first must understand the way ideology becomes dominate in a culture before you can talk about the rise of the proletariat against the bourgeoisie. Perhaps, Lerner would also explain that the conception of "us" against "them" must 
be laid to rest before human fulfillment can reached.

Despite these and other differences, these five white male European-descended individuals all have something to offer us today. As a collective, these individuals serve as examples of dialogue, critical thinking, personal action, and the barriers against them. As a synthesis of ideas, these examples help describe a cycle that includes ideological domination and how it gives way to personal action under the guidance of dialogue and critical thinking. A cycle, that if understood, holds great potential for any individual and any culture. 


\section{CHAPTER II}

\section{THEORETICAL FOUNDATION}

Dialogue, critical thinking, and personal action, as well as the barriers against them, are embedded in the works of many prominent Western thinkers. I have chosen to examine five such prominent thinkers, based on their conceptual relevance to this research. These concepts and their relationships will be seen through an examination of Socrates, John Locke, Karl Marx, Anthony Giddens, and Michael Lerner.

The following sections look at the ideas of these thinkers sequentially. The ideas that are observed and discussed focus on concepts, terms, and assertions that ultimately relate to dialogue, critical thinking, personal action and the barriers against them. It is important to note that each thinker presents an image central to a very important picture that has faded in and out of view through much of Western History. In other words, each thinker does not present the picture entirely, nor does he use obvious similarities to those that precede or follow him.

The ideas of these Western thinkers are significant both on their own and as they shape and shade the ideas of others. Ultimately however, these ideas offer a theoretical 
foundation for dialogue, critical thinking, personal action and the barriers against them.

OVERVIEW

Before delving into the theoretical foundation of this research, it is important to provide definitions of the key terms dialogue, critical thinking, and personal action. For the purposes of this research and analysis the definitions of these terms are not strict nor are they "borrowed" from any one school of thought. Rather these terms develop from the informal observation that has proceeded this research document. In other words the terms are in part shaped by the theories that have struck me as being vital to participation in U.S. democracy. Therefore, the following definitions are intended as a point of orientation.

Dialogue: purposefully directed interpersonal communication aimed at surfacing otherwise unrecognizable assumptions.

Critical Thinking: purposeful thinking directed at exploration, discovery, etc that brings to the surface and processes assumptions.

Personal Action: conscious action taken by an individual that they consider to be meaningful, significant, and otherwise a selfexpression of their power and ability to "make a difference" (ranging from personal to global). 
Barriers: those environmental influences, material or psychological, that tend to undermine any of the above (see table 1 below).

This chapter, and the one that follows, will provide further conceptual clarity about dialogue, critical thinking, and personal action as well as the barriers against them in society.

The table below helps to clarify how the ideas of the selected Western thinkers come together with the features central to democracy. Some of the descriptions in this table may be immediately familiar and others may be indistinct. Regardless, this table serves as a correlation of the ideas that will unfold. In other words, it is not required that these terms are immediately familiar as they will be explained in the forthcoming chapters. Table 1

\begin{tabular}{|l|l|l|l|l|}
\hline & Dialogue & $\begin{array}{l}\text { Critical } \\
\text { Thinking }\end{array}$ & $\begin{array}{l}\text { Personal } \\
\text { Action }\end{array}$ & Barriers \\
\hline Socrates & $\begin{array}{l}\text { Socratic } \\
\text { Dialogue }\end{array}$ & discovery & $\begin{array}{l}\text { attaining the } \\
\text { divine }\end{array}$ & assumptions \\
\hline Locke & $\begin{array}{l}\text { Public } \\
\text { Discourse }\end{array}$ & sharing ideas & $\begin{array}{l}\text { societal } \\
\text { balance }\end{array}$ & $\begin{array}{l}\text { tyranny \& } \\
\text { anarchy }\end{array}$ \\
\hline Marx & Dialectic & $\begin{array}{l}\text { Ilaying bare" } \\
\text { assumptions }\end{array}$ & $\begin{array}{l}\text { freedom (from } \\
\text { oppression) }\end{array}$ & $\begin{array}{l}\text { ideology (of } \\
\text { capital) }\end{array}$ \\
\hline Giddens & language & $\begin{array}{l}\text { tracking } \\
\text { ideology }\end{array}$ & $\begin{array}{l}\text { social } \\
\text { reproduction }\end{array}$ & $\begin{array}{l}\text { the modes of } \\
\text { domination }\end{array}$ \\
\hline Lerner & $\begin{array}{l}\text { Discussion } \\
\text { groups }\end{array}$ & $\begin{array}{l}\text { revealing } \\
\text { social } \\
\text { conditions }\end{array}$ & actualization & $\begin{array}{l}\text { specific } \\
\text { social } \\
\text { conditions }\end{array}$ \\
\hline
\end{tabular}


SOCRATES

According to Plato, [Socrates] had been struck by the Orphic doctrine that there are means by which the soul can be restored to remembrance of her forgotten divine origin, and from this hint he had developed the conviction that the acquisition of knowledge generally is in reality a process of "recollection" or "recognition" in which particular sensible facts prompt or suggest the assertion of a universal principle which transcends the facts themselves. By drawing a diagram and asking a series of pertinent questions, the mathematiclan leads a pupil to recognize a universal proposition. (Taylor, 1952)

Socrates demonstrates that dialogue, critical thinking, and personal action are related by way of discovery.

In Plato's Meno, Socrates puts several questions to a young boy. Socrates' dialogue with Meno's servant boy demonstrates how dialogue leads to a kind of thinking that promotes discovery. Inttially, Socrates' questions make the boy discover that he does not know a certain geometric principle. Later, the questions cause him to discover what he thinks he knows. Finally, the questions provoke him to discover that he does not know, but has found a pathway to discovery (Freeman, 1974):

Soc. Tell me, boy, do you know that a figure like this is a square?

Boy. I do.

Soc. And you know that a square figure has these four lines equal?

Boy. Certainly. 
Soc. And these lines which I have drawn through the middle of the square are also equal?

Boy. Yes.

Soc. A square may be of any size?

Boy. Certainly .

The questions continue and in mid-dialogue, Socrates notes to Meno the power of the dialogue:

Soc. Do you observe, Meno, that I am not teaching the boy anything, but only asking him questions; and now he fancies how long a line is necessary to produce a figure of eight square feet; does he not?

Meno. Yes.

Soc. And does he really know?

Meno. Certainly not.

Soc. He only guesses that because the square is double the line is doubled.

Socrates continues with his questions so the boy can

discover or "recall" the presumptions of his thinking. The boy makes some discoveries and then concludes with the answer "I don't know". Socrates turns again to Meno:

Do you see, Meno what advances he has made in his power of recollection? He did not know at first, and he does not know now, what is the side of a figure of eight feet; but then he thought that he knew, and answered confidently as if he knew, and had no difficulty; now he has a difficulty, and neither knows nor fancies that he knows.... If we have made him doubt, and given him the 'torpedo's shock', have we done him any harm?... We have certainly, as would seem, assisted him in some degree to the discovery of the truth; and now he will wish to remedy his ignorance, but then he would have been ready to tell all the world again and again that 
the double space should have a double line.

Socrates dialogue with Meno's servant clearly demonstrates that the process of dialogue is a pathway to discovery. By asking questions, Socrates helped the boy realize the assumptions present (but unrecognized) in his thinking. It is the assumptions and the processing of them, Socrates claimed, that are the keys to discovery.

Socrates' belief in dialogue, discovery, and unmasked assumptions was not restricted to mathematics and other academic discoveries. As mentioned previously, Socrates believed that dialogue was the means to "restore the soul to remembrance of her forgotten divine origin". For Socrates discovery was the way to reach the divine and to attain freedom (Rouse, 1956). Such goals were possible through the never-ending process of personal dialogue, as assumptions and discoveries are always lying in wait.

In Plato's Apology, Socrates announced to the world that "the unexamined life is not worth living" (Freeman 1970). His contention is supported by his own discoveries of the assumptions, attitudes, positions, and ideologies of the world that he participated in daily. Socrates own discoveries as well as his teachings were ultimately perceived as dangerously inappropriate by the Greek aristocracy. Ultimately, Socrates preferred to die than to 
be barred from making such discoveries about his society (a choice given to him by the aristocracy). His contention is also well-supported by the fact that he encouraged others to make their own discoveries by providing the necessary questions. In other words, Socrates taught others a process for discovery, not the discoveries themselves.

What becomes clear in considering socratic dialogue and the discoveries it brings forth is that there is a relationship between the one-to-one dialogue and individual assumptions and thinking habits. Furthermore, there is a clear relationship between the process of discovery and the outcome of discovery. Socrates saw and realized the great potential of dialogue to reach the divine and attain personal freedom. (of course, it can be said that Socrates died by the hands of the elite and consequently was not free. Yet, he chose death over banishment, and the choice is what made him free).

Chapter I noted that there are two components to personal action: willingness and ability. Socratic dialogue falls on the side of ability. If individuals engage in dialogue, then according to socrates, they engage in a means to discovery. This discovery, it has been shown, is ultimately about a process of dialogue, critical thinking, and personal action. Informal observation of American 
culture suggests that dialogue is notably absent, yet the common argument is that people are unwiling to participate.

\section{JOHN LOCKE}

General democratic theory demands that individual thoughts and actions be brought together for the purposes of social and personal welfare. According to democratic theories, a peoples' welfare depends upon individuals and is characterized by good and appropriate decision-making through discussion. Specifically, the work and ideas of John Locke help demonstrate that dialogue, critical thinking, and personal action are related by way of public discourse, specifically in terms of democracy.

There are several beliefs found in John Locke's concept of democracy that are important to public discourse and participation. First, Locke believed that individual participation is key to the form and function of government (Locke, 1689) -- without social actors there can be no government. Second, he believed that individuals have the ability to act meaningfully (to reason well and consciously) with regard to government (Wheelwright, 1954). Third, Locke believed that when government gains too much power it becomes oppressive (Carnoy, 1984). Fourth, Locke believed 
that when government becomes oppressive, individuals may leave the system (Baradat, 1991).

Locke clearly expected that government would be limited. To begin with, he never thought of government as being more than the sum of its parts. Unlike some political theorists, Locke believed that the state or government should never become more powerful than the individuals it served. (Baradat, 1991)

Before continuing with Locke, there are important distinctions to be made between the concepts of participation, non-participation, and the notion of "leaving the system". For the purposes of this research, "nonparticipation" must be considered a type of participation when it is a consclous choice made with the intent to affect the system. This is also reflected in the definition of personal action given in the overview to this chapter (p.11). For example, if an individual abstains from voting as a means to affect the system, then we may call that personal action. If an individual abstains from voting because they belleve they cannot affect the system, then we may call that a lack of personal action, or nonparticipation.

Out of John Locke's beliefs came the understanding that democracy was a process and that this process is aimed at maintaining a balance between tyranny and anarchy. In other words, democratic processes and outcomes cannot truly be separated--the distinction is artificial. 
Let us transport ourselves into a hypothetical country that, in a democratic way, practices the persecution of Christians, the burning of witches, and the slaughtering of Jews. We should certainly not approve of these practices on the grounds that they have been decided on according to the rules of democratic procedure. (Dye \& Zeigler, 1993)

This 1942 statement by Joseph Schumpter demonstrates and supports the point that making a distinction between democratic processes and outcomes is virtually impossible. According to Locke, if the outcome is not democratic, then the process was not democratic. He supports this idea in his Two Treatises on Government. Locke discusses how "the will of the majority" is not necessarily democratic, such as in the example of burning witches. Locke referred to such phenomena as "tyranny of the majority". Lockean democracy maintains that the purpose is to share ideas through group discussion and personal actions in order to maintain a society that is based neither in tyranny (extreme "law") or in anarchy (extreme "chaos"). The rule of democracy is therefore one of balance, expressed in the two-part objective of "majority rule with minority rights" (Glasser, et. al., 1991).

In the early $1800^{\prime}$ 's Alexis de Tocqueville travelled America and recorded many observations about American life. He observed Americans living in a democracy that was modeled after Locke's ideas, and noted the significance democracy 
had for Americans,

If an American should be reduced to occupying himself with his own affairs, at that moment half his existence would be snatched from him; he would feel it as a vast void in his life and would become incredibly unhappy. (Bennett, 1986)

These words indicate that Locke's concept of democracy and public discourse (virtually synonymous concepts) fulfills human needs and desires in a very significant way.

Taken together Locke's ideas are interesting given the observations in Chapter I concerning contemporary democracy. Chapter I noted that participation in contemporary democracy is on the decline. Furthermore, it was noted that this decline is frequently associated with widespread apathy. Locke might suggest that this is due to a government that has become too powerful--thus individuals are leaving the system by not participating. He might also reiterate that public discourse is necessary to encourage individual participation and the sharing of ideas, which is a primary defining characteristic of democracy. In a sense, Locke (or de Tocqueville) might say that the absence of public discourse in America today has indeed snatched "half [the American's] existence", leaving "a vast void in [their] lifen . 
KARL MARX

The dialectic, as such, explains nothing, proves nothing, predicts nothing, and causes nothing to happen. Rather, dialectics is a way of thinking that brings into focus the full range of changes and interactions that occur in the world. (Ollman, 1993)

The dialectic is a way of thinking that allows one to examine a set of conditions from more than one perspective. Marx examined his world in much the way Socrates did, examining (and critiquing) the assumptions and implications of the social conditions that surrounded him. Marx and his dialectic are yet another example of how dialogue, critical thinking, and personal action (and the barriers against them) are related. To clarify this comparison, the focus, perspective, and purpose of the dialectic must be examined. The dialectic focuses on the exploration of assumptions and implications. Karl Marx offered the dialectic as a means for "laying bare" ideologies and their assumptions. For example, in his famous work, Das Kapital (1867), Marx examined (among a variety of issues) the implications of a capitalistic economy:

The transformation of scattered private property, arising from individual labour, into capitalist private property is, naturally, a process, incomparably more protracted, violent, and difficult, than the transformation of capitalistic private property, already practically resting on socialised production, into socialised property. In the former case, we had the expropriation of the mass of the people by a few usurpers; in the latter, we have the expropriation of a 
few usurpers by the mass of the people.

Marx believed that few people were aware that they lived within an ideological system (whether 1 t was socialism or capitalism) or that if they were aware, they saw that ideology as inevitable (Carnoy, 1984). The potential of the dialectic lies in the notion that once individuals are made aware that they live within and as part of an ideological system that is not inevitable, they could (and would) act to change it. The dialectic was (and is) a particular way of thinking and of speaking.

Marx suggested this particular way of thinking and speaking was fundamental in understanding, operating, and participating in human systems (such as socialism or capitalism). If an individual does not know what kind of system they live within or that they live within a system at all, then their personal actions in daily life will differ significantly. This reasoning leads to the idea that the dialectic in itself does not have its main value in servicing a particular outcome. Rather its value is in the process of examining systems. The process cultivates knowledge, which simultaneously affects actions.

Marx's [dialectic], one might say, is to his theories what grand strategy is to the outcome of a war. It not only plays a decisive role in determining who wins (what works) or loses (fails), but helps define what either means. (Ollman, 1993) 
Marx was interested in laying bare ideologies and their assumptions because he had an interest in class systems. He had a special interest in those most oppressed by ideologies, the working class. Marx witnessed lower classes and workers living in a world they didn't like, that they were slaves to, not realizing they were participating in a system that could otherwise be different. Marx's use of the dialectic and what it lead to for him stands as an example of what the dialectic could do for others and makes the dialectic a process that engages personal action. The dialectic is a process of examining social conditions. This process allows the individual to see social conditions as a system or ideology, instead of a set of naturally occurring conditions. For example, Marx weighed the assumptions and implications of economic systems. This comparison allowed him to see that various ideologies were in place and functioning in various parts of the world. He also could see that others believed the social conditions that surrounded them (such as capitalism) were inevitable and inescapable. This thought is echoed in Marx and Engels, The Communist Manifesto (1848):

For how can people, once they understand their system, fail to see in it the best possible plan of the best possible state of society? ...the proletariat is still in a very undeveloped state and has but a fantastic conception and instinctive yearnings of that class for a general reconstruction of society... 
The thinking that led Marx to see a contrast of perspectives, was dialectical. The thinking that could lead the proletariat to move beyond "fantastic conceptions", "instinctive yearnings", and their "undeveloped state", is dialectical. By examining the assumptions and implications of a set of social conditions, the dialectic engages a variety of perspectives. The point is that seeing from many perspectives, frees a person from believing that one perspective (not seen as a perspective) is inevitable and inescapable.

Dialectical research is primarily directed to finding and tracing four kinds of relations: identity/difference, interpenetration of opposites, quantity/quality, and contradiction. (Ollman, 1993)

In other words, the dialectic is a multi-perspective exploration. A multiperspective approach is one that explores a system from several possible viewpoints and considers several relationships. Exploring an issue or concept like economics through many perspectives (such as communism and capitalism) reinforces the notion that social conditions are not inevitable or inescapable - more than one set of social conditions is possible.

The use of the dialectic fosters two important things. First, the process of thinking involved becomes more and more natural. Once an individual learns to examine a set of conditions as ideological in nature and from many 
perspectives, they then have acquired or developed a process of thinking that seems natural. In other words, their thinking is more easily focused on analysis and critique. Second, this process of thinking leads to a certain kind of freedom. For Marx, he was no longer constrained by social conditions that were inescapable. He saw the possibility that the various social conditions of the world could be different.

Marx's use of the dialectic begins with the disassembly of a system to lay bare its assumptions (Boggs, 1976). The dialectic is seen to have worked in this fashion as one examines the variety of discussion stimulated and furthered by Marx's works. Discussions regarding the state, Capitalism, Classicism, etc are found in works by Antonio Gramsci and Louis Althusser, for example, growing out of Marx's dialectical analysis.

The outcome of both Socratic dialogue and Marxist dialectic is a further awareness of the world in which one lives--the assumptions which bind the members to that world, and to the possible alternatives available. Such a process has significant implications for democracy. Individuals who possess the ability to perceive their world as a set of assumptions and who have alternatives and the ability to speak meaningfully about them, are individuals well-suited 
for the democratic model.

The dialectic is critical because it helps us to become critical of what our role has been up to now....A dialectical grasp of our society conditioned roles and the equally necessary limits and possibilities that constitute the present provides the opportunity for making a conscious and intelligent choice. In this manner does knowledge of necessity usher in the beginnings of real freedom. (Ollman, 1993)

\section{ANTHONY GIDDENS}

In his 1979 book central Problems in Social Theory: Action, structure and Contradiction in Social Analysis, Anthony Giddens critiques much of social theory and offers his own theory of structuration. Most significantly, this theory demonstrates how ideology becomes dominant in a system through various, but specific means, all of which center upon communication. Such a theory has implications for any system, especially for a democracy where communication is the focus. Such implications will be most explicitly explored in Chapter IV. This section emphasizes how the work of Anthony Giddens demonstrates that dialogue, critical thinking, personal action, and the barriers against them are related by way of power, language, and domination. To clarify this relationship this section will focus on the basic definition of structuration, the concept of time in 
the formation of structure, and the means by which ideology becomes dominant--i.e., the modes of domination.

Definition of structuration.

There are several key elements in structuration that may be expressed as follows:

- Where there is structure there are modes of domination

- Modes of domination are expressions of power relationships

- Power relationships manifest in ideology and language

Ideology and language interact continually and recursively

Giddens refers to 'those with power' as sectional interests. In other words, those with "interests" try to exercise power to create and maintain structures that will protect and enhance their interests. The structures that serve sectional interests are not truly fixed and tangible; rather they are expressed linguistically, ideologically, symbolically, and artifactually. The modes of domination are the means by which power is protected and enhanced through language, ideology, symbols, and artifacts. The process of enhancing sectional interests through language is continual. If some thing is a dominant artifact (for example), language may be used to discuss that thing as if 
it were fixed and unchanging--as if it were the only thing. When this language is heard, it reinforces the assumption that the dominant thing is the thing being discussed.

To give a concrete example, conslder a discussion about energy resources. Typlcally, if someone is asked "what is the most efficient way to heat my home", the reply will include a discussion of gas, oil, and electric heating (hydro-power). These are the dominant means of home energy in the United states. In a discussion about heating systems it is assumed that the available options are gas, oil, and electricity. The fact that this assumption is made then adds to the perceived dominance of the heating industries that include fossil fuels and large hydro-power dams (all commonly ecologically damaging resources). A discussion of any other type of heating system (i.e. solar and wind power) must be more carefully specified preclsely because it is not dominant; in a sense we would no longer be discussing "heating systems" as the phrase is habitually (perhaps even unconsciously) understood. This in turn contributes to the assumption that gas, ofl, and electricity (hydro-power) are "normal", even to the extent of assuming that they will always be the dominant means of heating a home.

Another useful example is found in the concept of a business. A person might say "I work for the XYZ Company". 
Their statement gives a sense that the company exists tangibly and continually in space--it is permanent. The words also indicate a relationship. The phrase "I work for" indicates that the person imagines themselves to be subject to the Company. Yet, social actors (people) are the makers of any organization (Mumby, 1988). A business is not a living entity, it does not have living tissue, independent thought, or communication abilities. Those that state, "I work for the XYZ Company" are actually the creators of the company's existence. Imagine the difference between the previous statement and someone saying "I frequently spend time with others creating business". The underlying assumptions that "the business" is somehow tangible, permanent, and living are no longer present.

Time, Space, and Repetition.

Anthony Giddens notes that much of social theory overlooks the important relationship between time, space, and repetition. The previous example, which demonstrates how language can shape thought and simultaneously present structures as fixed, immutable, and static (such as "the XYZ Company"), is an example of the relationship between space, time, and repetition. To clarify this relationship and its importance in structuration, the following section presents 
issues of language, the Sapir-whorf hypothesis, and the concepts of static and dynamic.

Giddens argues that our language is the "medium of social practice" and that "change or its potentiality, is thus inherent in all moments of social reproduction". Therefore, language not only reflects and shapes reality, but it also holds within it the change of reality. Giddens contends that the modes of domination reduce the potential for change through repeated language in time and space. Modes of domination are the means by which sectional interests are protected and served. Since modes of domination manifest in language, ideology, symbols, and artifacts, they manifest in communication. When individuals communicate they may communicate in terms of domination. Giddens references the Sapir-Whorf hypothesis to emphasize how this cycle of repetition takes place in time and space (Giddens, 1979). The Sapir-Whorf hypothesis explains how individuals concurrently shape, and are shaped by, language. According to the hypothesis, also known as Iinguistic relativity, our interpretation of reality is built upon our language habits, mostly in terms of how they manifest in cultural assumptions.

The fact of the matter is that the "real world" is to a large extent unconsciously built up on the language habits of the group.... We see and hear and otherwise experience very largely as we do because the language 
habits of our community predispose certain choices of interpretation. (Whorf, 1956)

As participants in our communities we are part of our own unconscious habit formations. Giddens explains how repetition enhances the self-affecting nature of language. In a simplified sense, the more often an individual communicates about something (like heating systems) the more likely they are to discuss it with the same words, concepts, and assumptions backing it (only gas, oil, and hydro-power, always gas, oil, and hydro-power). In this way, structures become perceived and communicated as fixed, immutable, and static, rather than perceived and communicated as flexible, open to change, and dynamic.

Modes of domination.

As previously suggested, power and ideology influence the formation of structure through communication. The modes of domination are the means by which that influence occurs. Before naming and describing the modes of domination present in Giddens' structuration theory, it is important to clarify Giddens' use of the term "domination". (In so doing, it is necessary to reiterate the distinction between domination in structuration and conspiracy theories.)

First, "modes of domination" is a phrase used to avoid the implication of a single dominator, just as Giddens 
defines "those with power" as sectional interests. This definttion is different from consplracy theories, which often involve a group of elites plotting and planning behind closed doors. Second, "mode" implies a way of acting or a pattern of action. In terms of structuration, a mode indicates a pattern by which ideology is carried in communication. Taken together these two aspects set aside assumptions that would imply an all-powerful being or group of beings manipulating everyone, everywhere to act precisely in a way that protects or enhances their power. Anthony Giddens' theory of structuration offers three modes of domination:

1. The representation of sectional interests as universal interests.

2. The denial or transmutation of contradictions.

3. The naturalization of the present: reification. Additionally, Dennis K. Mumby noted that the discussion and role of hegemony (participation in one's own domination) in structuration theory was significant enough to warrant it as a fourth mode:

4. The identification of self within the values and goals of dominant interests (i.e., hegemony)

Taken together these four modes constitute a pattern of domination. In short they explain how an ideology becomes unobservable as it becomes the ideology. 
This section will describe these modes of domination in order to clarify how dialogue, critical thinking, and personal action are related via Giddens. The first mode (that sectional interests are represented as universal) is largely explained by the two principles that (1) ideology and power are carried in communication, and that (2) communication is the medium of social practice. In terms of our dominant fossil fueled and hydro-powered heating systems, the idea that "what is good for business is good for America" may find expression in the notion that these heating systems are a big-business money maker, and that's good for everyone. This (dominant) sectional interest is presented as universal, in spite of other (non-dominant) sectional interests, such as high personal and environmental costs that impact individuals.

The second mode (the denial or transmutation of contradictions) is another "means" that protects dominant power and ideology. Extending our example, consider the rhetorical contradictions between two episodes in energy resource practices. Episode 1: During the 'gas crunch' of the 1970's there was a push to conserve: automobiles were made more efficient and alternative energy systems were explored. The Carter Administration established tax breaks for those installing solar heating in their homes, etc. The 
rhetoric of dominant interest held that business and market forces would provide any necessary changes in the industry as there was both demand and profit for such products. Episode 2: During the 1980's company's like GM and GE shelved any new, alternative technologies as consumers acclimated to higher energy costs. The Reagan Administration cut solar tax breaks, etc. In support of dominant interests, the rhetorical argument held that it was in everyone's interest to support the economy by buying consumer goods. In the first episode, a hands-off approach is always best for everyone. In the second, we must step in and help or all will suffer. Even while the first mode of domination is called upon to justify each rhetorically contradictory act, the rhetoric consistently supports dominant interests. The contradictions necessary to support dominant interests are obscured and transformed to fit the situation. (of course, this example does not constitute "proof" of the second mode of domination, and may be considered a hypothetical example for the purposes of this research.)

The third mode (naturalization of the present, or reification), involves the assumption of particular conditions and meanings of things, events, and ideas. As assumptions become ingrained in language and attitudes, 
things seemingly become "natural". Again, following the example, the statement "I work for the XYZ Company" comes to carry with it an assumption that the company is somehow tangible and permanent. In other words, reification is the fixing of structure: what is present in the world today has always been a part of the world because it is the natural order for society. Examples that contradict this assumption are not only "un-normal", but are also unnatural.

These modes of domination at first may draw a picture of the world that renders individuals without power to change 1t. Giddens is very explicit in this:

Power relationships are always two-way; that is to say, however subordinate an act may be in a social relationship, the very fact of involvement in that relationship gives him or her a certain amount of power over the other. (Giddens, 1979)

Since communication is the way ideology and power are carried, all individuals have power. By using the term "alternative heating systems" instead of "heating systems" for example, individuals may expose or track ideology and observe that structure is not fixed, immutable, or static. However, Giddens explains that individuals participate in their own domination by using communication that does treat structure as fixed, immutable, and static. This was identified by Dennis Mumby as the fourth mode of domination, hegemony. Clearly, when taken together, these modes 
constitute a pattern of domination, a way that ideology is communicated so that it becomes dominant:

Anthony Giddens, critiques social theory for ignoring the role that time plays in social construction and overlooking human actors and language as the means of social construction. Giddens' theory of structuration emphasizes that "society" is not a fixed structure--that individuals are social actors that create "society" through language and other forms of communication. In a sense, Giddens' theory of structuration describes how language, if taken for granted and used habitually, without a certain kind of conscious thought, will result in ideological domination. Conversely, however, Giddens' ideas suggest that the power of conscious communication is that it can keep track of ideology and assumptions.

Just as Marx can be seen to have developed the dialectic to lay bare ideologies and their assumptions, Giddens can be seen to have described the power of communication as a way to track ideologies and their assumptions. While Marx personally applied the dialectic to discuss systems of human construction, Giddens outrightly discusses communication as the means for the daily reproduction of systems. Both lead to the notion that without knowledge of Ideology (systems) individuals will 
take daily actions with only surface level thinking--a significant notion when considering the argument that participation in the U.S. is on the decline due widespread apathy .

The escape of human history from human intentions, and the return of the consequences of that escape as causal influences on human action, is a chronic feature of social life. (Giddens, 1979)

\section{MICHAEL LERNER}

Powerlessness corrupts. Powerlessness corrupts in a very direct way: it changes, transforms, and distorts us. It makes us different from how we would otherwise want to be. We look at our world and our own behavior, and we tell ourselves that although we really aren't living the lives we want to live, there is nothing we can do about it. We are powerless. (Lerner, 1991)

In his book, Surplus Powerlessness: The Psychodynamics of Everyday Life... and the Psychology of Individual and Social Transformation(1991), Michael Lerner theorizes about powerlessness. Lerner emphasizes the important relationship between individual action, personal welfare, and social change. Lerner suggests that individual powerlessness transforms into surplus powerlessness due to a series of oppressive social environments. This "surplus" or excess of powerlessness immobilizes individual action, devastates personal welfare, and consequently prevents social change. Again, such a set of ideas has implications for democracy, 
especially given contemporary observations such as low voter turnout and individual pessimism concerning government and change. These implications and observations will be discussed in Chapter IV.

Lerner demonstrates that dialogue, critical thinking, personal action, and the barriers against them are related by way of surplus powerlessness. Specifically, this section will explain Lerner's ideas about what powerlessness and surplus powerlessness are, what causes them, and how they can be transformed.

Powerlessness.

I don't want to make it seem as if there is nothing but psychological problems standing in the way of social transformation. It is precisely people's assessment of their real powerlessness in many of these struggles that plays an important role in keeping them from getting involved in the first place. (Lerner, 1991)

Lerner makes a distinction and establishes a relationship between (real) powerlessness and surplus powerlessness. Powerlessness, according to Lerner, is the recognition and acknowledgement of social conditions that make some individuals or groups more equal than others. For example, there is an awareness in the U.S. On the part of most individuals that the U.S. embodies a class system, that there is a group of individuals that constitute an elite class, and that elites have more resources (power) than the 
lower class. However, real powerlessness does not negate the potential of change despite such soctal conditions-everyone has some power. Surplus powerlessness is the perception that an individual is completely without power. Lerner references his own experience with the 1960's SDS movement (students for a democratic society) as an example:

What I was startled to discover was that the real accomplishments, the real victories, achieved by all that effort were continually being discounted by my colleagues in the movement. Instead of crediting what they had done, they described the reality in a way that made themselves seem even more powerless than they actually were. Moreover, they took this powerlessness as axiomatic, expected it, and then acted to insure that it would remain the case. (Lerner, 1991)

What Lerner describes is the relationship between the two forms of powerlessness--how real powerlessness became surplus powerlessness. For Lerner, the SDS members were always aware that others were invested in the status quo, primarily the elite. At some point however, he witnessed some members of the SDS internalize this awareness to a more significant degree. The significance was that these individuals began to act on that internalization and began to act as if they had not or could not create social change. This episode for Lerner, brought forth the question, why do transformations like this take place? 
Causes of powerlessness.

Lerner claims that it is the manifestation of general social conditions that transforms powerlessness into surplus powerlessness. Lerner discusses the state of and conditions that surround individuals in the U.S. today. Lerner maintains that the isolation and fragmentation that accompany work and family life in the U.S. constitute the "oppressive social environments" which create surplus powerlessness.

Lerner begins explaining these oppressive social environments by noting that individuals seek actualization: "human beings have a need to actualize their capacities for loving, creativity, freedom, solidarity, and understanding..." (Lerner, 1991). There are several outgrowths of the system that undermine actualization: success and failure; role-playing and fragmentation; family units and isolation; stress. Each of these are significant, and according to Lerner stem largely from the work environment. However, the undermining of actualization begins with language and childhood.

The language of "reality," the language that constitutes the world for us, simultaneously proclaims to us that the world as constituted is justly constituted. The very act of entering the linguistic system means entering into a world of meanings in which the fundamental fairness of how things are set up is assumed and asserted. (Lerner, 1991) 
Generally Lerner observes that real powerlessness is carried in the linguistic system. Another observation of Lerner's is that "the parent communicates in hundreds of subtle and unconscious ways [to a child]." A third observation is that "the parent conveys to the child that the child is a set of roles" (Lerner, 1991). Bringing these observations together Lerner suggests that entering into the linguistic system (a virtually unavoidable experience) is the beginning of the struggle to actualize.

On the surface Lerner indicates that this struggle often takes the following form: An individual feels frustrated, stressed, and underappreciated at work. They seek a relationship or family situation that will "fix it", that will make the work environment tolerable. Since they carry the frustration and stress with them into the relationship, the relationship is unhealthy. since the relationship is unhealthy, the individual engages in pathological behavior such as excessive television, drug abuse, more work, etc. At some point the individual may recognize this behavior and seek help. Therapy and other self-help books and organizations emphasize the role personal responsibility plays in the shaping of one's life. Thus, the individual develops a sense that they have failed not just as a worker and a partner, spouse, or parent, but 
as a human being.

While this description is an oversimplification, and

Lerner himself emphasizes (among other things) that work and family life are constantly affecting each other, this description clearly identifies a pattern or process that is not otherwise clear. Lerner suggests that if it were clear, then therapy, self-help books, and other forums such as drug abuse clinics or stress management courses would emphasize both responsibility and the systemic nature of these problems.

Psychology, I quickly discovered, had its own ideological framework, neatly coincident with the dominant ideas of American society. Just as the larger society claims that it is set up in a fundamentally fair way, in which people can make it if they really try, so psychology explains powerlessness as a product of the individual's personal failures. (Lerner, 1991)

What Lerner discovered in beginning his investigation of powerlessness was a dominant ideological framework that sets up both the scale by which success and failure is measured and the mechanism that indicates how to solve failure with more individual responsibility. The scale is problematic because it is not about measuring actualization. The mechanism is problematic because it subscribes to the scale, and therefore it is not about actualization either. In short, according to Lerner, the dominant ideological framework of the U.S. is carried in language and manifests 
in conditions that do not support or encourage individual actualization.

Instead of actualization, the dominant Ideological framework offers isolation and fragmentation that is reflected in the above description. Lerner specifically points to how life becomes compartmentalized in this framework. Work, family obligations, social activities, etc. are separated from one another and the process that undermines actualization is not identifiable. Most significant (in Lerner's view) is that through the fragmentation comes isolation.

Individuals come to believe that they are solely responsible for their failure according to the scale that measures success. Individuals also come to accept the fragmentation and compartmentalization of daily life. According to Lerner both seem to be a natural part of living. In thinking that these conditions are natural, the individual does not question the scale, but rather themselves. In questioning themselves the individual ceases to discuss social conditions and effects with others simply because their "failure" is quite logically their fault. So instead of discussing the social conditions and acting to change them, individuals vent, complain, or otherwise speak aloud their problems and act as if they are failures (recall 
the SDS example). It is important to note that the processing of complaining or venting may not speak directly of personal failure. Rather, individuals may lay blame to other people or social conditions for their own dissatisfactions. When discussion is replaced by exclamations of personal failure there can be no effective recognition that the conditions may be oppressive, that individuals are not solely responsible for "failure"; that many experiences such as frustration and stress are symptoms of oppressive conditions and most significantly, that the conditions can be changed.

The transformation of discussion to exclamation or venting is a signal that the road to actualization is cut off just as individuals are isolated and cut off from one another. This transformation is surplus powerlessness. In summarizing Lerner it is clear that language carries the dominant ideological framework that establishes the ("natural") social conditions which undermine actualization and lead to fragmentation and isolation.

Transforming surplus powerlessness.

The next question for Lerner was, how to undermine the undermining? In other words, what would prevent or undo the transformation of powerlessness into surplus powerlessness? 
Lerner recognized that it was not the ideology or the oppressive social environments that needed to be (or could be) directly changed. Instead he reasoned that anything which was counter to isolation could be a starting point. If isolation was more or less the final outgrowth of the oppressive social conditions, that it was surplus powerlessness, then undermining isolation might undermine surplus powerlessness.

Several years ago Michael Lerner began what he calls "Occupational Stress Groups". These groups attract a wide range of workers - office workers, medical technicians, mechanics, etc. Lerner discusses with them the surplus powerlessness and the various ideas which surround it such as stress in the workplace, fragmentation, the appearance of these conditions as natural, etc. Alongside this discussion are a number of exercises that take place in and outside the group sessions. These exercises require that the group members share with each other their goals and desires, their frustrations, their feelings of self-blame, their dissatisfaction with work, and what they would liked to see changed. These exercises also require that the group members ask co-workers and family members to share the same kind of information.

These groups are initially set up to last twelve weeks, 
but according to Lerner they usually last months or years. The enduring nature of these groups is largely dependent upon how members are encouraged to present information and what happens with the information that is shared. By undermining surplus powerlessness, these occupational stress groups result in altering worldviews. Lerner emphasizes that the process is a very delicate one, that there is an enormous margin for error. Members often seek a constant forum for "bitching"; others reach out in ways that engage human sympathy, but still uphold the conditions that undermine actualization; still others quite naturally feel a resistance in shifting worldviews and such feelings must be acknowledged and carefully handled.

Through the occupational stress groups the members feel less isolation because they realize that others have had the same experiences they have. The members come to realize that these experiences are not their problems or their fault --in fact they realize that placing blame is not the issue. By acknowledging these feelings and realizations, the members recognize that they are not completely without power, that their workplaces (for example) are oppressive and can change. Many members become active in their unions, others join PTA groups, political party campaigns, or other activist groups. In short, the occupational stress groups 
undermine surplus powerlessness and move toward

actualization through careful discussion.

The Stress Groups do not themselves attempt to become action groups in the unions, except to support their members in whatever activities they are engaged in. The stress Groups have one substantive goal besides supporting their own members: to encourage other people to join stress Groups, or in other ways participate in those kinds of discussion of the details of their life at work and in family life, so that they too can begin to discover the ways that they have been inappropriately blaming themselves and repressing their anger. (Lerner, 1991)

In the U.S. today there are two commonalities that directly parallel Lerner's observations. First, there is the observation that participation (in many arenas) is on the decline such as voting or activism. Second, there is a common attitude of "I can't make a difference--what does one vote dop". Given Lerner's work, these commonalities again bring to mind the relationship between being willing to participate and being able to participate. If a person perceives they are not able to participate meaningfully, then they will not participate despite their interest.

\section{CHAPTER SUMMARY}

Socrates, Locke, Marx, Giddens and Lerner all piece together in their own way how dialogue, critical thinking, personal action, and the barriers against them, are related. 
Socrates shows how dialogue develops thinking that promotes discovery and freedom. Locke shows how public discourse is fundamental to personal welfare (filling an otherwise vold in human existence that creates "incredible unhappiness"), and social welfare (maintaining a balance between tyranny and anarchy). Marx's use of the dialectic shows how analytical and critical thinking can develop, and how it can create a certain sense of freedom (the world is not made up of inevitable or inescapable social conditions). Giddens shows how the modes of domination (through language) maintain a dominant ideology and make it appear as natural and inevitable.

Each of these Western thinkers has embedded within their Ideas significant pieces of a fundamental relationship: that dialogue engages critical thinking, and that both together can promote personal action by (in part) penetrating the barriers against them.

Chapter III will further explore this relationship of concepts. When brought together in chapter III, the composite of Socrates, Locke, Marx, Giddens, and Lerner will even more clearly demonstrate that the relationship of dialogue, critical thinking, personal action, and the barriers against them is both real and present, especially where today's U.S. democracy is concerned. 
CHAPTER III: SYNTHESIS

A synthesis of these Western perspectives reveals that particular forms of communication should be able to overcome the barriers to personal action in a democratic society. This synthesis begins with a discussion of power and personal action. Next is a brief description of the barriers and how they form. Finally, this chapter concludes with a description of the means of penetrating these barriers and how such penetration is simultaneous to enabling personal action.

POWER AND PERSONAL ACTION

Power and personal action are closely related. If one perceives they have power they will take action, conversely if one perceives they do not have power they will not take action. Given this basic assessment, a continuum of power can be drawn:

Power Powerlessness $\quad$ Surplus Powerlessness

When examining Giddens and Lerner together the relationship of power and personal action becomes clear. First consider Giddens' notion that no matter how 
subordinate one is in an interaction or relationship they have some power. Then consider Ierner's notion of surplus powerlessness--that one perceives and thus acts, as if they have no power. Giddens and Lerner, it appears, would agree that social conditions tend to exist where power collects, leaving some individuals with more power or less power than others. This is what Lerner calls powerlessness (a perception that someone has more power than you or that you have less power than them). This is also what Giddens refers to when discussing a "subordinate relationship". Lerner goes on to explain that some individuals come to believe that they have no power whatsoever and that they live their lives acting as if they have no power, thus reinforcing their perception (the Sapir-Whorf hypothesis, see page 30 ). This is the point where the relationship between power and personal action becomes strikingly clear. Again the question axises, how does a perception of having no power develop?

\section{BARRIERS TO PERSONAL ACTION}

The same social conditions that create an inequity of power, create barriers to personal action. It is important to keep in mind that a discussion of the barriers to 
personal action is also a discussion of surplus powerlessness. In other words, a perception of having no power translates into living without acknowledgement that one's actions can be meaningful. This section will discuss the supposed social conditions that make this happen. These social conditions are most clearly described by Giddens as the modes of domination and by Lerner as work and family conditions that isolate and fragment. However the other thinkers presented in this work are also found to contain hints describing these social conditions. Therefore this section will primarily focus on these barriers drawing primarily from Giddens and Lerner, but will also include a brief and worthwhile look at Socrates, Locke, and Marx. Socrates, Locke, and Marx each hold elements that when drawn out, provoke questions about the barriers to personal action. For example, Socrates describes in the Meno how unrecognized assumptions in one's thinking are the barriers to discovery. Locke also touches on social conditions that affect personal action. He quite thoroughly discusses the difficulties of oppressive government and how it is counter to public discourse and democracy. Marx thoroughly discusses the conditions that spawn class division and the need for laying bare the assumptions of various economic ideologies. With regard to both Socrates and Marx, one 
might ask "where do these assumptions come from and how can it be that it takes such effort to discover them (dialogue) or to lay them bare (dialectic)?" While these examples may be less obvious than Giddens and Lerner, they are no less significant.

Through a consideration of Giddens and Ierner specifically, a set of observations can be derived:

Dominant ideology becomes dominant through means which make ideology appear as natural and unchanging.

- Dominant ideology remains dominant through its hidden appearance and through hegemony.

Dominant ideology grows and prospers through breaking down those processes which would reveal it or lessen the hegemony.

These observations explain how social conditions that are barriers to personal action arise and perpetuate. It is important to remember that when discussing dominant ideology and the means by which it occurs, it is not a discussion of conspiracy. Language and social actors are the basic elements of social construction. The modes of domination denote a pattern, or a way that language and social actors tend to act that allows an ideology to become dominant. Once set in motion there is an almost mystical quality to the perpetuation of any one idea, let alone an entire ideology. Yet, the basic components have not altered-language and social actors are those that construct society. 
As both Giddens and Lerner explain, language is the way in which ideology is carried. Giddens explains this describing how language is both inherently ideological and the means of social construction. Lerner explains this by describing (for example) how parents communicate to their children that they are a "set of roles" (see p.41). Consider socrates and the slave boy once again: how is it that the servant came to believe that he knew mathematics as he did? Where do the assumptions of one's thinking originate from? In considering Giddens and Lerner, the answer becomes clear through the language that individuals use to construct society. There is a collective process involved.

This collective process has room for some assumptions and ideas to become dominant through certain processes. Dominant ideology becomes dominant through means which make ideology appear as natural and unchanging. Now consider again the example of heating systems and energy resources (p.28). In the mid-1800's the possibility of centralized industry became much more clear. Those who had resources available sought out this potential. Thus, when Henry Ford built the combustion engine automobile, or when Edison and Tesla built the first power plant, those who had invested in the potential of industry expanded their resources. As 
presented in history books and modern discourse, the progression of the automobile and the electric home appear as the natural course of human invention and evolution. The phrase "you can't stop progress" is common enough in the arena of technological development. Using Marx's dialectic and even some of his analysis, questions are easily raised as to the capitalistic motives that urged the industrial revolution. Would the automobile have been developed without capital investors? Would the automobile have become so popular, prominent, and common without capitalism? Without the drive to industrialize? The same questions can be asked about electricity and other energy resources. This example demonstrates that social conditions are not necessarily natural or unchanging.

Once established, an ideology remains dominant through its hidden appearance and through hegemony. Giddens modes of domination illustrate the subtle nature of ideology. Even when individuals discuss, examine, and critique their immediate environment, the critique is often limited. For example, one might discuss how the U.S. government and corporate lobbyists deny the potential for alternative energy sources because it's not in their interest. As Lerner observed, the discussion is limited in that it is centered on complaint rather than on action. The outcome of this 
scenario is often a dissatisfaction with the conditions that one must obviously endure-- (following the energy example,) "I hate the system for making oil, hydro-power, or gas heat the only available choices." This brings together the hegemony discussed by Giddens and the sense of failure, blame, and complaint discussed by Lerner. Ultimately, this example is a very real illustration of how dominant ideology remains dominant and how it begins to affect personal action. The growth and perpetuation of dominant ideology is not limited to affecting isolated cases of limited personal action. Dominant ideology prospers through breaking down those processes which would reveal it or lessen the hegemony. Lerner's observations show how dominant ideology lead to the isolation and fragmentation of the individual. The workplace incorporates a certain way of measuring success and failure, where the successes are not comonly fulfilling and the failures are just common. He notes that stress in U.S. culture (and in any culture that shares the "protestant work ethic") is considered a natural part of the human condition. But, when looked at more closely, the common occurrence of ulcers and heart attacks in young men, and frequent insomnia are recognized as unnatural. These cultural occurrences, coupled with the prevalent assumption of self-help rhetoric proclaiming that one is solely 
responsible for one's happiness, does not make for communicative individuals. Who wants to discuss these cultural conditions when the response is commonly limited to two choices: "Yes I agree, the world is unfair" or "Well if you don't like, it change it!" These responses are understandable considering those who share the environment are often thinking with the same dominant ideological assumptions. Equally understandable is the choice to 1solate one's self. According to Lerner, powerlessness quickly becomes surplus powerlessness under these conditions. Social conditions are seen as a set of seemingly insurmountable barriers to personal action.

With regard to U.S. democracy, this isolation and these barriers against personal action are easily identified in statements such as "Why vote? One vote can't make a difference," or "That's just the way things work, things will never change" (a statement especially common in discussion of government and politicians). The issue of a willingness to particlpate is much less prominent than the issue of ability to participate, given the observations drawn from this composite of Western thinkers. More importantly however, is the final question that now arises: How is surplus powerlessness to be transformed--how is personal action enabled? 
DIALOGUE AND CRITICAI, THINKING

An examination of these Western thinkers demonstrates that dialogue and critical thinking are fundamental to enabling personal action. This relationship is clarified through a series of observations:

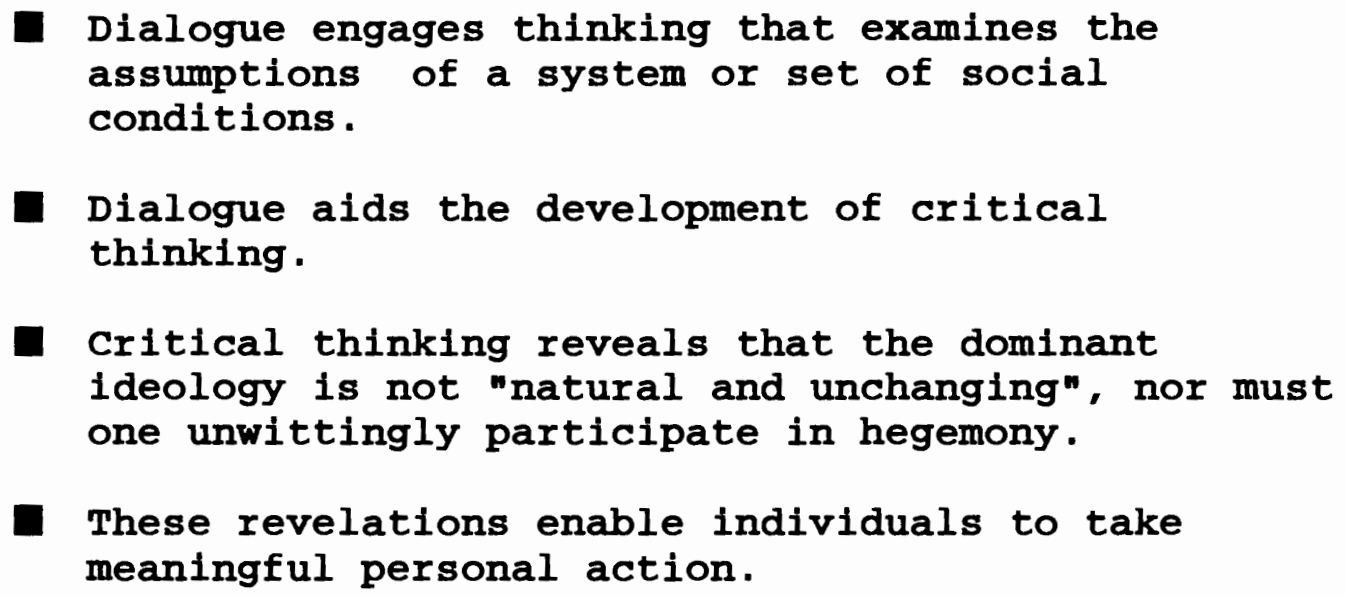

Socrates, Locke, Marx, Giddens, and Lerner all offer pieces that clarify these observations.

In other words, we must "argue ourselves out of our present thinking and into thinking that is more or less novel to us if we are to gain genuine knowledge. We need others, therefore to help us in this "argument", to probe and question our thinking as a contrast that enlivens and stimulate's our's. (Paul, 1990)

The first observation (listed above) is most obviously supported by Socrates. Socratic dialogue is explicitly aimed at discovering assumptions through communication. Locke's process of public discourse also highlights the role that discussion plays in sharing ideas for personal and 
social welfare. Lerner's design of "occupational stress groups" aims specifically at unmasking the assumptions that a person has made about their own condition--including their power and their actions. Socrates, Locke, and Lerner all directly point to dialogue as being a process of examining assumptions .

The second observation is most clear in placing Socratic dialogue alongside Marx's dialectic. Processing individual and cultural assumptions through dialogue sets a person on the path of developing their own thinking. Socrates taught his students a process for making discoveries, not the discoveries themselves. Marx's dialectic is a form of thinking that can more readily occur once a person becomes practiced at analytical and critical thinking through dialogue.

Critical Thinking: 1) Disciplined, self-directed thinking which exemplifies the perfections of thinking appropriate to a particular mode or domain of thinking. 2) Thinking that displays mastery of intellectual skills and abilities. 3) The art of thinking about your thinking while you are thinking in order to make your thinking better: more clear, more accurate, or more defensible. (Paul, 1990)

The potential of the processing of assumptions via dialogue and critical thinking is present in the work of all five thinkers. This is not to say that each philosopher outrightly speaks of the relationship between dialogue and critical thinking. Rather, this is to say that if applied 
to their ideas, dialogue and critical thinking take on significant meaning. For socrates this potential is in living a worthwhile life, as happens through discovery. For Locke this potential is in maintaining a societal balance through public discourse. For Marx, this potential is in laying bare the assumptions that bind people to the social conditions in which they live (thus "laying bare" their path to freedom). For Giddens this potential is in tracking ideologies in language so as to identify them and the patterns by which they become entrenched. For Lerner this potential is in dissipating surplus powerlessness and striving for actualization.

Each of the above descriptions sets a foundation for the third observation: that critical thinking reveals dominant ideology as being something other than natural, unchanging, and hegemonically inevitable. Perhaps the automobile might not have become so common even in a capitalistic system, if individuals had dialogically reasoned the implications of mass production as well as the mass use of automobiles. And, perhaps there would be less acceptance of the hegemonic statement "you can't stop progress". Again, the same consideration could be made about the earlier example of heating systems and energy resources. It is likely that renewable energy sources would 
be more prevalent if dominant ideology were not so subtle and so easily perceived as natural.

The revelations that dominant ideology is not natural and unchanging, and that one does not have to accept hegemony strike at the heart of personal action. Once the world is no longer a set of inescapable and inevitable conditions, there is a sense that a person is no longer bound to those conditions. Furthermore, if a person recognizes that language and social actors are the building blocks of society and that society is reproduced from moment to moment, then there is an even greater sense that one can act meaningfully. In other words, one realizes that they are social actors that shape society (Giddens, 1979). The members of Lerner's occupational stress groups are a primary example of these revelations. The members see the social conditions that have led them to experience isolation, failure, self-blame, victimization, and other experiences that deny actualization and that undermine personal action. They see these conditions as ideological in nature and they see that in their isolation they came to accept and participate in that ideology. Upon these realizations, the members begin to engage in personal actions that are meaningful to them by joining groups such as a union, the PTA, a political party, or an activist organization. Once 
again the notion that U.S. citizens are unwilling to participate must be considered. Given this synthesis of philosophy and theory, it seems quite clear that barriers to an ability to participate occur in the larger social conditions. When these barriers are penetrated ability matches willingness and people do participate.

CHAPTER SUMMARY

Dialogue promotes critical thinking. Together, dialogue and critical thinking are the means to penetrating the barriers of assumption, and are also the means to enabling personal action. This chapter has presented a synthesis of several Western perspectives. This synthesis has revealed that particular forms of communication should overcome the barriers to personal action in a democratic society. The next chapter offers a discussion of these implications. This discussion focuses upon several arenas that are central to the social conditions of $\mathrm{J.S.}$ culture. These arenas include the systems of mass media, education, the workplace, and government. 
CHAPTER IV

DISCUSSION \& IMPLICATIONS

The three preceding chapters have discussed the relationships between dialogue, critical thinking, and personal action. Dialogue and critical thinking work toward penetrating the barriers of assumption and work toward enabling personal action. This set of relationships, has importance for all aspects of human social interaction. In this chapter the significance these concepts and their relationships have for the system of mass media, educational systems, the organization of work, and governmental systems are discussed. Oltimately, this chapter demonstrates how these common social arenas tend to foster rather than penetrated ideology and how they undermine rather than enable personal action.

These systems will be examined through a variety of historical, philosophical, theoretical, and present day observations. The primary context of these discussions is that of U.S. culture. This discussion is based on trends that are common in J.S. culture (rather than on a exhaustive survey of the trends and their exceptions).

By showing where and how dialogue, critical thinking, 
and personal action are present, absent, or otherwise misdirected in U.S. culture, the realm of positive available possibilities for individuals and society become clearer. 
IMPLICATIONS FOR MASS MEDIA

A prerequisite for democracy is that citizens be willing to participate and be able to participate. A variety of democratic models, including John Locke's, stipulate that having access to the means of public discourse is vital if democracy is going to occur. The mass media has its origins as a means of public discourse. Discourse in this sense does not necessarily refer to the simultaneous communication that we often assume today. Rather, it refers to the public exposition and exchange of thoughts and ideas in any form. Public discourse by its nature is communication by citizens intended for citizens. At the time when the founding fathers formalized American government, speech and the press were the primary means by which citizens of the 13 states could and did communicate about federal issues - - the press was a channel for discussion (Dye \& ziegler, 1993). Today, a conceptualization of mass media as a forum of public discourse is awkward and unfamiliar to us. Mass media has expanded in its forms and its functions. Television, radio, magazines, and newspapers present a range of information, persuasion, and entertainment to their audiences. Common observation indicates that today's mass media feels like an 
entity unto itself that presents information. The question is, do these forms and function still fulfill the purpose of public discourse? If they do not, then, are there viable means for today's United States citizens to effectively communicate with each other, and with those that represent them in government?

These questions will be explored in the discussion that follows, but first it is important to note the impact of the answers. If mass media does not fulfill the purpose of public discourse and if there appear to be no viable alternatives, then there are two possibilities. First, that people of the U.S. no longer live in a democracy, and are not interested in such. Second, (and much more compelling) that the people of the U.S. need to find, encourage, and make effective a means of public discourse so that democracy might thrive.

\section{MASS MEDIA, PART I:}

Mass Media as Public Discourse?

This discussion begins with an overview about the nature of mass media research. However the primary focus is on four specific questions:

1. Is mass media infused with ideology and domination? 
2. If "alternative" solutions and policies exist to dominant ones, does mass media effectively discuss them?

3. Can and do ordinary and private citizens effectively access mass media to address the citizenry at large?

4. If an interaction between mass media and citizens exists, does it promote social change?

These questions help ascertain whether or not mass media serves as a means of public discourse in today's U.S. culture.

Mass media and Ideology.

Research on mass media raises many questions. Does mass media shape opinions or just set the agenda of opinions? Does mass media affect the social attitudes of audiences? Does mass media hinder, help, or initiate soclal change by affecting individual attitudes? More recent understandings of mass media discount direct causal relationships between mass media and the thoughts and actions of its audiences. Instead, direct causality is replaced by indirect influence.

It may be more realistic to think of the media as contributing to - but not controlling - the structure of publicly-available information that shapes the way people can and do think politically. (Entman, 1989)

Today's mass media research reveals this influence to be significant. Many current theories look to mass media as a highly influential element upon the flow of information 
which shapes individual experiences and therefore perceptions .

To reiterate, I am arguing that the mass media now provide the dominant formats for an expanding round of social activity by helping establish, sustain, and map social order. (Altheide, 1985)

It is important then to examine further mass media given this description or role. Charles L. Bosk asks a set of vital questions and initiates this examination:

Why do toxic chemical wastes in landfills receive more public discussion than dangerous chemicals in America's workplaces? Why do so few weep for the dying rain forest? The extent of the harm in these cases cannot, in itself, explain these differences, and it is not enough to say that some of these situations become problems because they are more "important". (Bosk, 1988)

Indeed there are many occurrences in the world that are unjust or otherwise intolerable, even by the standards put forth by the dominant ideology of one system or another. Reviewing why or how issues become noticeable when others do not, sheds further light on this examination of mass media:

Media frames are persistent patterns of cognition, interpretation, and presentation, of selection, emphasis, and exclusion, by which symbol-handlers routinely organize discourse, whether verbal or visual.... Any analytic approach to journalism -indeed, to the production of any mass-mediated content - must ask: What is the frame here? Why this frame and not another?...And then: What difference do the frames make for the larger world? (Gitlin, 1980)

According to social and media theorist Todd Gitlin, it is the nature of the mainstream media to portray a certain 
picture of the world - - to provide particular information is to not provide other information. This phenomena is known as media framing and clarifies how mass media highlights certain information.

By itself, media framing is not problematic -- it is just another way of explaining individual perspective and how a variety of views concerning a single event can exist. However, media framing becomes problematic when issues are framed in a consistent manner, meaning that there is a pattern to those views and little variety.

News is managed routinely, automatically, as reporters import definitions of newsworthiness from editors and institutional beats, as they accept the analytical frameworks of officials even while taking up adversarial positions. When reporters make decisions about what to cover and how, rarely do they deliberate about ideological assumptions or political consequences. Simply by doing their jobs, journalists tend to serve the political and economic elite definitions of reality. (Gitlin, 1980)

This observation of Gitlin's is found in other research of mass media (Page, et. al., 1987; Ball-Rokeach, 1986; Lazere, 1987).

Additional support for the presence of ideology in mass media comes from the more common public rhetoric regarding the "liberal" or "conservative" bias of the media. This rhetoric (found at dinner tables, editorial pages, and political debates) indicates that mass media does hold 
within it the shadow of ideology.

This general overview of mass media theory indicates that there is a tendency for mass media to present a world view largely in line with the dominant 1deology of the system in which it operates. This notion is also consistent with observation and reasoning regarding individuals and domination: if individuals are commonly subjected to the modes of domination, then mass media would be as well, mass media is produced by individual effort. This tendency will be further supported by observations made in the next section.

The effects of ideology and the modes of domination, combined with the effects of media framing, undermine mass media's potential as a medium of public discourse. The effects are that mass media occurs in an environment that (naturally) limits the variety of perspectives. This has an impact on the range of alternatives presented in the mass media, as will be discussed in the next section.

Mass Media, Ideology and Alternative Thinking.

The concern or argument arises that alternatives to dominant ideology are presented in the mass media. If this is so, then issues of ideology and domination in mass media might be rendered less problematic. This concern is 
addressed by existing research that examines the character of discussion within mass media.

In pursuing media effects studies it is quickly discovered that the mass media criticizes problems of the status quo (dominant ideology) within a narrow range.

Television news provides a picture of the world which renders radical social changes invisible, undesirable, and unnecessary. In the complex interplay of mediated and situational culture the crucial contribution of television news is to contain social change by failing to provide the values and symbols which would provoke or sustain it. (Golding, 1981)

This "failure" by the media makes any presented alternatives acceptable because they are safe alternatives for the dominant ideology. For example, "writing your congressional representative" is a commonly heard way to protest policy whereas standing on a street corner holding a sign of protest or staging a public fast are not as far as mass media reports are concerned. (Although public gatherings and demonstrations were considered important enough to warrant constitutional rights and protection (Dye \& ziegler, 1993\}). Locke's concept of democracy presents public discourse as the means by which the balance between tyranny (extreme law) and anarchy (extreme chaos or "the state of nature") is maintained. Possibilities and alternatives are presented and discussed so as to find the "best" possible action or policy (for maintaining the balance). If mass media limits 
the range of alternatives, mass media limits discussion so that the "best" may not be discovered. This limits the potential for maintaining the balance. Research and observations such as Bosk's (p.69) and Golding's (p.73) indicate that alternatives are not widely. presented in the press. Again common observation also supports this notion of limitation: The weekly poll has become a common feature of the press. These polls frequently offer an either-or scenario "do you favor or oppose gun controlp", "should the federal deficit be solved be 1 ) cutting social spending or 2) raising taxes?". Such questions and their results perpetuate a limited view of possible solutions.

Mass Media and Citizen Access.

Further investigation into mass media and alternatives reveal information about audiences and access. Even if alternatives are presented to the audiences of mass media they are not presented as possible actions, but as distant events. Expanding on this idea it could be supposed that issues may indeed be discussed by audiences, but as sterilized information, not as fuel for citizen action. Additionally and perhaps more conclusively, reasoning and general observation support the claim that individuals do not commonly engage in mass media as public discourse. 
The most effective medium for reaching the citizenry of the U.S. (in an effort to engage in public discourse) is through national television. Does the average citizen readily have access to this medium? clearly the answer is no. This observation alone can deny mass media as a forum for public discourse.

Mass media and Social change.

Even if ideology is incidental to mass media, even if alternatives are presented, and even if audiences commonly have access to mass media, the question remains as to whether or not mass media promotes or encourages social change. The notion that the mass media negates or retards any change from the status quo has been at least partially substantiated so far. However, media researcher Peter Dahlgren offers further support in his concept of "non-reflexive viewer consciousness".

Dahlgren argues mass media denies reflexivity in three ways. The first is through technology and what Dahlgren calls "officialdom". Viewers wonder not only at the omniscient power of news -- (it can report from anywhere to anywhere in a matter of moments,) but it also postures an air of credibility through specialty language, etc. The second mode of non-reflexivity speaks directly to the notion 
of social change:

Viewer consciousness is socialized to be essentially inefficacious. The public are rarely presented as social actors who shape the social world. The domain of acceptable citizen activity is extremely limited. (Dahlgren, 1981)

Finally, the media denies reflexivity through separation from the past. The viewer can neither learn from history, nor learn how to reconclle current issues through recognition and identification of past experiences (Dahlgren 1981). In other words a citizen concerned with issues of immigration, could not readily connect policies during WWII to now. The issue would not be framed in the mass media in terms of comparison nor in terms that speak of action. Instead, it would be framed in terms of immediate policy (as if in a vacuum) and in terms of "reporting the facts that have happened today" .

Democracy is not only dependent on public discourse but on social change (Dye \& Ziegler, 1993). Changes in the construction of society move along the continuum of law and chaos, creating social conditions that are more or less tended toward one end of the continuum. Social conditions are never such that society has reaches and maintains a perfect balance between tyranny and anarchy -- democracy is a process that pulls social conditions back and forth along the continuum. However, as Giddens points out power and 
ideology tend to gather more power through the modes of domination. Such a trend will tend to pull social conditions in one direction or the other (tyranny or anarchy). Without effective public discourse that is focused upon changes in social conditions, power and ideology will become all consuming (at least for some period of time, i.e.. the Roman Empire, Nazi Germany). This being the case, it is vital that the means of public discourse include discussion of social conditions and social change. As has been observed, the media do not discuss issues in this manner, and therefore do not provide a means of public discourse.

Summary of Mass Media, Part I.

By reviewing mass media theory, it can be concluded that mass media does not present itself as a forum of public discourse. Mass media is not about social actors, nor is it for social actors. If democracy depends upon public discourse where social actors discuss a full range of alternative actions, then mass media should be characteristic of public discourse. Yet as this discussion has demonstrated mass media is typically ideological in nature, presenting a limited range of views and treating individuals as consumers and passive audiences -- all of 
which negates or discourages social change. At this point the discussion must turn to the vital question, if not the media, then who? In other words, if mass media is not the means of public discourse, then what is?

\section{MASS MEDIA, PART II:}

Alternative means of Public Discourse?

We, [the evil dinosaur...media] don't matter anymore. Today the big noise comes from talk radio.... E-mail and other tech talk may be the third, fourth or nth wave of the future...

- -Richard Corliss, magazine writer

A forum for public discourse must be available if democracy is to be assumed viable. Frequently when concerns are raised about the viability of mass media as a means of public discourse, people say it isn't so and that citizens can participate. "Talk Radio" exemplifies an entire category of popular mass media that is held in support of contemporary means by which individuals communicate about a variety of issues. Additionally, there is a new trend and technology that has potential as an alternative to traditional mass media -- computer mediated communication, specifically "the net". This section will explore both possibilities. 
Talk Radio.

Recent years have seen a proliferation of talk radio type programs. Over 800 "talk stations" have sprung up in the last ten years, capturing a rough $15 \%$ of the listening audience (Time, Jan. 1995) These programs feature a host who frequently takes on a topic or theme for the day and casts out a variety of bold statements. The host might begin with or interject during the program, a lengthy editorial. These statements and editorials motivate listeners to call in to the station and offer opinions or ask questions. The nature of the opinions vary from "radical" to "mainstream" to "interesting", etc. The callers may speak for a few seconds to a few minutes. This format has also translated into television. The Rush Limbaugh show is a blend of talk show and talk radio. This show focuses on "political" content as opposed to "personal" (-my mother-married-the boy next door-) content. Yet, the format is that of the typical afternoon talk show where audiences applaud, raise objections, etc.

These formats seem to have potential as a means of public discourse. They collectively discuss a broad spectrum of issues where audiences contribute a their viewpoints. These programs have a regular, interactive audience who are heard by a substantial audience themselves. 
However, when looked at more closely, there are reasons for doubt. This section will explore each of the four characteristics that help define public discourse in terms of talk radio.

There is a dominant theme of Republican conservatism found in talk radio. Common critiques of the medium hint that conservative Republican representatives use the means to promote their names and their policies (SFD, 1993). Regardless of which ideology is dominant, there is wide support for the notion that talk radio is not just saturated with ideology and domination, but that it is a tool for ideological domination (Peck, 1995). If talk radio is to be an adequate medium for public discourse, then ideological viewpoints would have to be more balanced and less observable.

The high concentration of conservatism in talk radio also limits the variety in discussion. While many issues may arise, the viewpoints are few. There is also a phenomena of disconfirming communication in talk radio. There are people who call in or speak out in ways that oppose the claims of the host or other audience members. However, such opposition is frequently communicated in a hostile manner or at least is reacted to in a hostile manner. This hostility can encourage similar opinions and 
attitudes and discourage differing opinions. A limited and hostile environment must be altered if it is to promote public discussion that airs a full range of views and considers them as well.

The third defining characteristic of public discourse is that of common national access. While it is true that there are many talk radio programs, only a handful of them are national. There is more possibility for communication with the local citizenry than for communication with the national citizenry. Also with its conservative bent, talk radio is not likely to be considered worthwhile by a significant percentage of the J.S. citizenry.

National address was once much more accessible to the average citizen than it is today (Glendon, 1991). This concept of national address is an important one if public discourse is to select the "best" of all possibilities. Discussion of advantages, objections, alternatives, etc. is essential to weighing possible actions. Talk radio provides little opportunity for audience members to make such contributions on a regular basis, nationally.

Even if national talk shows were the rule and not the exception, the host is still the primary "star" of the show. For example, criticisms of the Rush Limbaugh Show are mostly about Rush Limbaugh -- who he is, what he represents, his 
character, etc. For a medium to fulfill the role of public discourse access must be commonly and readily available, not just a chance for "five minutes of fame".

The concept of hostility in talk radio also addresses the issue of social change. Michael Lerner emphasizes the difference between communication that is habitual venting and communication that is about dispersing surplus powerlessness. Those that conduct the occupational stress groups must insure that members don't engage, promote, or otherwise encourage each other in complaining about circumstances (thinking that promotes the "I can't change it" attitude). Rather, the members discuss circumstances in terms of possibility and alternatives (thinking that promotes social change). People who call in to talk radio programs are heard to be expressing opinions that are often inflexible, judgmental, and complaint-oriented. They are less frequently heard to be asking questions or to be expressing an openness to alternatives. In other words talk radio is not characterized as a source for promoting social change.

If we still gathered at town meetings, if our churches were still community centers, we wouldn't need talk radio. People feel increasingly disconnected, and talk radio gives them a sense of connection. (Time, Jan 23, 1995)

- Marvin Kalb, former CBS reporter, adjunct at George Washington University. 
struggling for connection is struggling for the conditions that support personal action (in Lerner's terms "actualization"), and in this sense, for democracy. However, the struggle found in talk radio today is more about venting than it is about social change. While talk radio may have potential, it has a long way to go in becoming an effective means of public discourse.

\section{The NET}

A more promising medium for public discourse is that of computer mediated communication, referred to here as "the Net". In terms of mass media and technological development, this medium is very new, yet it has had a tremendous impact. This impact is the initial reason the Net is discussed here as a potential forum for public discourse. This discussion of the Net will examine each of the four characteristics that define a medium as one of public discourse.

While computer mediated communication intimidates some, it holds great potential for most individuals. This medium seems to meet the basic definition of public discourse. There is no consistent pattern of ideology present on the Net (yet). A range of topics and viewpoints are discussed, as well as available as public information. Users have not just national, but international access to a broad and 
diverse audience (including political leaders). Finally, the Net promotes discussion that is more about social change than about venting and complaint, (although both occur).

The Net is neither owned nor operated by government agency, corporate interest, or some form of collective conglomerate power. There are a variety of access points to the Net and some are more commercial and corporate than others (compare America on-Line to any local backroom business such as Portland's Teleport, Inc.). Yet, the Net is so vast in who can connect with whom and what data is available, that there is little opportunity for a consistent pattern of domination to take hold...so far. Concerns about heavy government regulation or corporate control are common in discussion about the Net, as is political maneuvering by politicians. However, as it stands today the Net is a forum that is free of a single coherent ideology, being full of individual ideologies.

Keeping with the above theme, the Net does have available information to users that concern a range of topics and alternatives. Information varies from publicly available government documents to sexualiy explicit material to job announcements. The primary concern with this issue is that the Net is too large in scope. A user must look for information - - it won't come looking for them. For example, 
if a person is interested in information concerning efficient home energy choices, they might find data on electricity, oil, natural gas (all common to dominant capitalist ideology), as well as data on solar and wind power (typical alternatives to this dominant ideology). However, until they begin their search, no information will come to them on the Net. This can translate into a disadvantage (in terms of public discourse): that finding information and connecting with others can be intimidating. There is a question as to if and how this might be remedied and if such change is advantageous.

The third defining characteristic of public discourse is common access to a national audience. The Net is beginning to fulfill this criteria. Those that are on-line do have everyday access to any number of people across the globe. Users can contribute and subscribe to particular groups that vary in purpose, membership size, and rules of conduct. Users can also talk in "real-time" to a single person or a group of people. The most important issue with this characteristic is how common access is to the Net. Although computer sales are constantly on the rise, subscriptions to on-line packages are steadily increasing, and methods of free Net access are available to the public at librartes, the total percentage of those who regularly 
access the Net is very small. House speaker Newt Gingrich, recently advocated the Thomas program. This program, named in honor of Thomas Jefferson, is aimed at increasing that percentage so that the Net can be essentially a public forum. However, there are doubts as to the viability of Gingrich's proposals as congressional advocacy frequently overruns itself in a rush of political gridlock.

The final issue that must be examined regarding the Net, is the promotion of social change. This is perhaps the least certain and clear of the four issues. The Net may be largely free of ideology, have available a variety of issues, and even provide regular national access to all users, but does it promote or encourage social change? Discussions on the Net include cartoon song lyrics, discussions about Madonna's new hairstyle, etc. There is a question as to whether or not these discussions maintain a balance or promote social change.

On the other hand, the general mass media, politicians, and corporate executives are already jumping on the opportunity to reach the potentially untapped audiences, or they are busy negating such potential. Why does a Time magazine cover state, "electronic populism threatens to short-circuit representative democracy," (emphasis added) and why does the article itself focus on "hyperdemocracy"? 
Why does an article in the oregonian have a secondary title, "Cyberspace can be dangerous for candidates"? Why does a magazine cover picture Bell-Atlantic CEO, Ray Smith, stating "cable is dead" and feature an article where he discusses his work to protect the Net from government regulation? If the Net didn't hold potential for social change, it's unlikely such headlines would be written, let alone the articles themselves.

It would seem that the Net holds more promise as a medium of public discourse than talk radio does. However, the above observations lead to a few objectives specific to the Net that may aid its viablility as a forum of public discourse. First, users of the Net must keep it safe from both heavy government regulation and corporate control. Second, Users need to examine and possibly create a more cohesive system of organization to the avallable data. Such a system might make finding and attracting information easier. Third, users need to support and encourage programs like Thomas so that access is more global. When taken together it is likely that these objectives will make the Net into a medium where dialogue can foster critical thinking and promote personal action. 
IMPLICATIONS FOR EDUCATION

Without critical thinking at the heart of ethical instruction, indoctrination rather than ethical insight results.... No culture sees itself as indoctrinating its young or discouraging intellectual development. Each sees itself as concerned with education worthy of the name. The rhetoric of reason and objective learning is everywhere. Yet classroom instruction around the world, at all levels, is typically didactic, one-dimensional, and indifferent, when not antithetical, to reason. (Paul, 1990)

Even though it is argued that much social learning takes place before children reach school age, it has traditionally been the place of the educational system in the United States, to teach skills and present knowledge collectively that parents, families, and communities individually cannot teach (given the current standards of social organization). As the previous chapters have established, the core of democracy is a citizenry that is both willing and able to participate. It has been contended that citizens in the U.S. are interested and willing to participate, but that they experience a series of conditions (modes of domination) that create an "I-can't-make-adifference" attitude. It has also been demonstrated that the relationship between critical thinking and dialogue represents a means by which willingness to take personal action is engaged. This leads to the notion that the educational system in the U.S. has performed a disservice 
and an injustice by failing to promote critical thought and communication.

There is an extensive background in history that places education as a foundation to social interaction and to government. John Stuart Mill, Kant, Marx, John Dewey, Jean Piaget are just a few of the well known philosophers that have given thought to the shape and form of formal education. This section does not paint a detailed mural of all those who have contributed to education. This section does provide a basic sketch of the thinking that has shaped education in the U.S. today, and into the future by way of dominant ideology.

This section will discuss historically significant trends that have impacted the United states educational system and will end with a discussion about the future. Dltimately, this section raises and answers several important questions as well as making some crucial observations.

Questions :

1. What is the purpose of an educational system?

2. What do the various classroom styles promote, such as an authoritarian style?

3. Does the United States have a public, private, or state educational system?

4. Who is a child, what does it mean to be a child, and are children to be educated as property? 
Observations :

1. A specific ideology and the modes of domination are present in the educational system.

2. Both ideology and the modes of domination in the educational system effect feelings of powerlessness and personal action.

3. Dialogue and critical thinking are uncommon in the educational system.

These questions and observations are key to understanding where the educational system maintains barriers to personal action. The term system here deserves emphasis -- to say that critical thinking is uncommon for example, is not to say that it does not exist. There are many examples of educational reform, experiments, and particularly individual classrooms that demonstrate the qualities of dialogue and critical thinking. The question is not whether we can find examples of "good" education, the question is "can we find evidence that the educational system encourages and serves these qualities?"

As a sidenote to this discussion, it is important to remember that the barriers to dialogue, critical thinking, and personal action are not always obvious or even accepted once made clear. This discussion makes several observations that show where philosophies and ideologies put in motion many decades past, manifest in education today. This discussion also observes how those manifestations are 
barriers to dialogue, critical thinking, and personal action. Many of us are concerned and dedicated to education and know there are both downfalls and advancements in the system today. As you read, consider the student's perspective, especially that of the K-12 student (their stories of their experiences as a $k-12$ student are very telling about the system today). Also consider your own assumptions of learning and teaching. I know I have caught myself making statements in the classroom that upon later reflection (or student observation) I discover to be narrow, assumptive, and potentially detrimental. As individuals concerned with education we must consider both specific, individual communication in the classroom and general, collective trends in the educational system.

THE FOUNDATIONS OF MODERN EDUCATION: Historical and Philosophical Background

Formal schools in the United States date back as far as the first settlers arriving on the Eastern shores. However it wasn't until the mid-1800's that attendance to formal schools became more regular and consistent throughout the states (and territories). Children were attending school roughly 200 days a year (up from 80 ), but they still only 
attended school, on average, for 1 to 2 years. By the late 1800's the federal government had taken a more active role in the forms and purposes of education -- a trend that has endured and will likely continue, into the 21rst century. This four hundred years of educational transformation has seen not just the proliferation of schools and student attendance, but also a progression in the purposes and reasons children are sent to school.

The first 200 years of American education were mostly based on purposes of discipline and morality (Paul, 1990):

"Free schools were set up, as in Massachusetts (1647), "to teach all children to read and write... (to combat) that old deluder Satan," or (1675) to ensure that "children and servants" are "catechized". In Plymouth Colony (1671) "Education of Children" was mandated because "Children and servants" were "... in danger (of) growing Barbarous, Rude, or stubborn" and hence were becoming "pests".

Such reasons certainly did not (and do not) promote critical thought and communication.

Investigations during the mid-1880's by philosophers and various school boards, raised concerns about the nature of education. In an 1838 report to the Massachusetts Board of Education, Horace Mann, reveals the degree of learning in schools :

I have devoted especial pains to learn, with some degree of numerical accuracy, how far the reading, in our schools, is an exercise of the mind in thinking and feeling and how far it is a barren action of the organs of speech upon the atmosphere.... The result is that 
more than $11 / 12$ ths of all the children in the reading classes do not understand the meanings of the words they read.

such findings were not uncommon. Concerns about the condition of education came primarily from two modes of thinking. First, there was the notion that government was formulated on the basis of an informed public. If children were failing to learn and therefore unable to participate meaningfully in government, then education needed to change. Second, the nation was rapidly growing due to the industrial revolution that included advancements of machinery and transportation. There was concern that unlearned and untrained children would not necessarily help effectively foster the growing U.S. industry.

Both modes of thinking were played out in federal investigations of education at the turn of the century. In 1893, a document entitled "Report of the Committee of Ten on Secondary school studies" was published. Twenty five years later in 1918, another significant document was publish entitled, "Cardinal Principles of Secondary Education". Both documents contributed greatly to the development of modern education (Hirsch, 1987).

The first document made an argument for classical education - the study of Greek, Latin, languages, the sciences, literature, etc. This argument was based on the 
premise that standardization and a well-cultured populous should be cultivated. If schools are standardized by instructing students in classical arenas, then at least those who are schooled are exposed to subject matter that is known for scholarship and culture.

This argument and it's premise were later rejected on the assumption that some children were naturally inclined to learn such classic subjects and others were not (some students are naturally "smarter" than others). Thus, the second document made an argument that education should be standardized by goals, not by subject matter. The report outlined several principle aims that included both "vocation" as well as "citizenship" and "command of fundamental processes" (Hirsch, 1987). The values implicit in the report presented the goals of education as those of democracy and societal development. Yet, the policies that manifested from the report focused on social utility, pragmatism and ultimately, vocation.

The rejecting of the classical subject matter was partially based on the notion that some children are just not capable of learning it (Hirsch, 1987; Dewey, 1938). (An notion that has been disproved by theorists such as Jean Piaget.) This lead to the idea that children should be taught according to their (obvious) abilitles. Some would 
receive a more classically-oriented education and other would receive a more vocationally-oriented education.

This assumption was carried faithfully on into post World War II America. The further development of industry and business combined with the assumption that some are destined to a certain level of understanding, sustained a division between which students learned what:

A [1948] resolution passed by educators meeting in Washington, D.C., asserted that only 40 percent of our children were being properly educated. Twenty percent of American youth were being prepared for vocations, while another 20 percent were being prepared for college... (Hirsch, 1987)

It was at this time that state governments began commonly setting forth educational legislation. Laws were made that set minimum standards as to who could attend which school, and for how long. Typically, students were required to attend school through the eighth grade (or fourteen years of age). Expanding government spending made more funds available for the schools.

However such support did not overcome the heavy toll already incurred by the struggle several decades previous, between the purposes and foundations of an educational system. A struggle that led to and perpetuated the understanding that schools and education are to prepare students for economic participation (producing, selling, buying consumer goods, etc). In other words, the schools 
were assumed (by governmental policy) to be a training ground for the larger economic workplace. Educational standards are guided and regulated by governmental legislation. One example where the assumption of education as a training ground and governmental regulation come together is found during the era of sputnik. The was a sudden focus on math and sciences directly following the launch of Sputnik, the first successful attempt at space exploration - - accomplished by America's foremost competitor, the Soviet Union. Standardized tests were distributed to schools across the nation to assess the math and science skills of America's students. This is not to say that more focus on these skills wasn't necessary or that it undermined education. Rather it is the reason for focusing on these skills that provides evidence for concern. This reason equates with the motives of competition and superiority on the part of business and industry. While such concerns created support for further development of the educational system, they also guided that development in a particular direction. Education could be determined "successful", as long as it could be measured by short-term, quantitative, and standardized methods (i.e. "Are we, the U.S., winning the space race? Are our students equal to their Japanese counter-parts in math, science, and 
history?")

Today, at the closing of the 20 th century, there have been gains in the educational system and there are many downfalls. Federal government funding has made school buildings available, provided transportation to get students to those buildings, and has established wages for teachers and staff. Yet, high percentages of students drop out of school and many complete high school without knowing how to read. There is also a disparity between those students who go to college and those who do not. There is also a disparity between schools -- some schools and districts have a significantly higher quality of education than others. More interesting and significant however, is that regardless of the path a high school graduate takes (fouryear college, military, Jr. college, or vocational training) or the quality of education they receive, the focus is largely the same: which career is the student pursuing? This question has grown out of the philosophies, policies, and thinking that was set in motion several decades (and centuries) ago. 
MODERN EDUCATION

Schools and workplaces are organized in ways that correspond closely. Both tend to be large, bureaucratic, impersonal, hierarchical, and routinized. Both tend to motivate performance with external rewards such as grades and wages, rather than depending on the value of the enterprise itself. Schools and workplaces alike are dominated by expertise and formal authority; in both there are schedules that determine the timing of work, and regulations that determine its nature. It has even been suggested that these institutional resemblances are no mere accident - - that schools are specifically designed to prepare young people to function in the bureaucratic hierarchies that they will join as adults. (Carnoy and Levin, 1985)

This observation from the work of Martin Carnoy and

Henry M. Levin, Schooling and Work in the Democratic state, summarizes the trend that the 1918 report (and it's supporters) initiated. The Cardinal Principles report was based on two assumptions: that citizens should not be governed without their consent (thus the need to develop an active citizenry) and on the idea that students are naturally attuned to a certain level of intelligence (thus the need to develop a diverse curriculum that can offer appropriate courses to the intellectual abilities of the students). As time passed these assumptions developed at odds with each other, as work and industry have become the dominant motivation for education and the concept of an informed, critical citizenry has remained educational rhetoric rather than practice. The work of Carnoy and Levin 
offer a perspective that it is the struggle between democracy and capitalism that has led to the conditions seen in today's educational system. This struggle plays itself out in both the content of the classroom and how that content is taught.

Learning here means acquisition of what already is incorporated in books and in the heads of the elders. Moreover, that which is taught is thought of as essentially static. It is taught as a finished product, with little regard either to the ways in which it was originally built up or to changes that will surely occur in the future. It is to a large extent the cultural product of societies that assumed the future would be much like the past, and yet it is used as educational food in a society where change is the rule, not the exception. (Dewey, 1938)

Dewey notes a phenomena common to the educational system, a phenomena that is akin to isolation and Giddens''s modes of domination. Perhaps one of the first criticisms of classroom content one hears by students is that it is "dull" or "dry and boring" (remember high school history class and its textbooks?). An investigation into such comments might reveal that they are akin to the situation of content in time. If content in the classroom is presented in the static fashion Dewey suggests, then there is evidence that education does not escape the modes of domination. For example, if history is presented as "factual" without consideration given to perspective and interpretation and it is presented as "stuff that happened", giving no indication 
that past policies affect present and future actions, then students are already cut off from the idea that they are the makers of history --that they are social actors. An examination of many of the history texts commonly used in today's K-12 classes reveal that there is a tendency for the texts to present a static view of the world. Also consider the common organization of the school day to be arranged in classes by topic - - an hour of science, an hour of math, an hour of english, etc. Often there is little overlap between the subjects. So for example, Einstein becomes known as the scientist who discovered the theory of relativity and his work as a poet and a diplomat are left unknown to the student.

Further examinations of contemporary classroom content reveal not only the presence of the modes of domination, but the ideology that is manifest through the modes of domination. Frequently, readings and lectures are full of language that is patterned and consistent in the sense of domination (Carnoy and Levin, 1985). This pattern includes language that denotes ethnocentrism, heterosexuality, anthropocentrism, American patriotism and economic superiority, etc (Paul, 1990; Bloom, 1987; Hirsch, 1987). There is also, as previously discussed, the dominant ideology of capitalism - education as a training ground for 
future employment, etc.

It is important to remember that domination happens in such a way that it is not obvious - as Richard Paul says, "no culture sees itself as indoctrinating its young". This means that there are many educators in $\mathrm{K}-12$ schools (and beyond) who will discuss how they do not support or encourage such views. However, it is the assumption that language is a neutral tool for teaching and the habitual uses of words that often hides our own participation in domination (hegemony).

How material is taught is another means by which ideology (and the modes of domination that encourage it) thrives in the classroom. It is also the means by which critical thought and communication suffers (if it is not altogether extinguished).

To imposition from above is opposed expression and cultivation of individuality; to external discipline is opposed free activity; to learning from texts and teachers, learning through experience; to acquisition of isolated skills and techniques by drill, is opposed acquisition of them as means of attaining ends which make direct vital appeal; to preparation for a more or less remote future is opposed making the most of the opportunities of present life; to static aims and materials is opposed acquaintance with a changing world. (Dewey, 1938)

There is strong evidence in the work of many educational thinkers that the methods used in most classrooms do not promote learning and discovery in the Socratic sense. John 
Dewey and Jean Piaget are two of the more prominent and well-known of these thinkers. Both assert the need for experience as a means of learning and discovery over methods of rote memorization, authoritarian style classrooms, and other such trappings (Dewey, 1916; Piaget, 1969). For example, experimenting with paper airplanes and a fan, a student begins on an experiential path of learning physics as opposed to sitting in row four of six exposed to a lecture about vectors. Consider the following statement made to educational researcher Richard Paul:

After I started teaching, I realized that I had learned physics by rote and that I really did not understand all I thought I knew about it....students asked me questions for which I always had the standard textbook answers, but for the first time it made me start thinking for myself, and I realized that these canned answers were not justified by my own thinking and only confused my students... To achieve my academic goals I had to memorize the thoughts of others, but I had never learned or been encouraged to learn to think for myself.

Lecture oriented classrooms contribute to the shutting down of critical thought and communication by not being able to maintain dialogue --if questions get asked, they are answered in a non-critical, "textbook" fashion. They also contribute to the shutdown of critical thought and communication by encouraging a more authoritarian atmosphere --rule-bound, schedule-oriented, set completion dates ("due dates"), and measurable output ("correct" answers). This 
atmosphere is not one in which students will easily answer questions (what if the answer is wrong?), much less generate new and different thinking that leads to discovery. Also consider the basic physical design of a classroom: most often the desks students sit in face the "front" of the room where the teacher stands and lectures. It does not take an extensive background in communication theory to know that this design would not promote a conversational or otherwise dialogic atmosphere as easily as a circle of desks or a setting where everyone sits, including the teacher. This is not to say one should be abandon to the other, this is merely an observation that the standard arrangement is not the most likely way to initiate dialogue.

Another way content and method of instruction undermine discovery is found in the nature of "authority". Dewey's comparison (p.102) notes the common method of "imposition from above" as opposed to discovery. In other words, "the acquisition of what already is incorporated in books and in the heads of the elders" is the source of learning. Commonly found in classroom presentation, textbooks, and exercises is an underlying assumption in education that learning is about external "facts" -- knowing who said or did what, and when. (An assumption which has been born out of the "education as a training ground" philosophy set in 
motion several decades past.) This concept of learning overlooks the internal source of learning, which Socrates, Dewey and Piaget discuss. Both the external and internal sources are important for learning, especially if critical thought and communication are to develop.

There are two other issues that (although seemingly tangential,) have extreme significance for this discussion of education: the concept of the "child" and the concept of a "public" school system. Modern U.S. cultural assumptions of what a child is, is reflected in the schools. It is important to note with the following discussion of both of these issues that they are being addressed as systemic assumptions. If the system is found to harbor certain assumptions that undermine dialogue and critical thinking, then the instances of alternatives and progressive philosophies are undermined as well. In other words, one teacher, one class, one parent, one student etc. working counter to the system does not represent the difficulties of the system, but rather represents the struggle against them. Additionally, rhetoric of all kinds addresses the problems and issues of today's public school system without ever defining a "public school system". Perhaps, some of the problems and issues would be redirected and more successfully solved by the public and the politicians upon 
considering these terms and their definitions.

The child.

Throughout much of Western history children have been regarded as "belonging to" their parents, at least until they reach a certain age. Presumably this idea grows out of parental concern that children are vulnerable and need protection. On the other hand the same attitudes were made about women and blacks. A woman couldn't own property because women weren't considered capable of handling financial matters, thus laws made them unable. The same was true for the free black man. The right to vote was denied to both women and blacks on the same basis (Greenburg \& Page, 1994). Yet, at the same time concern was high that citizens were being ruled without their consent,

The opposition tells us that we ought not to govern a people without their consent. I answer: The rule of liberty, that all just government derives its authority form the consent of the governed, applies only to those who are capable of self-government. I answer: We govern the Indians without their consent, we govern our territories without their consent, we govern our children without their consent... (U.S. Senator Albert Beveridge, 1899).

It is easy to balk at such rhetoric knowing what has been established in previous chapters: that all individuals are capable and interested in participation if access is available. What is difficult to accept is the idea that 
children are equally capable if access were available to them. Does this mean that the future holds emancipation and suffrage for children as the past has provided for women and blacks? These movements did not begin with goals of property ownership and voting rights, they began with principles of individual rights and autonomy. An important issue that intersects education and domination is our culture's assumptions about what individual rights and autonomy, an issue that includes our culture's concept of what defines a "child".

According to Neil Postman's The Disappearance of Childhood (1982), the division between "children" and "adults" is a relatively new concept. Postman observes, for example, that in historical records there is no mention of "teen marriage" or "children having children". In other words, people were people and took actions for good or 111 . In many cultures past and present, infants and the very young are members of the community upon their birth (or before). These younger members contribute to community projects as well as community discussions. In these communities "rites of passage" are not about becoming an "adult" (and thus leaving childhood behind), they are about welcoming new worlds of possibility (the thrill of joining the hunting party, for example). Rites of passage were (and 
are) determined by tests of ability and motivation, and not by arbitrary age designations.

Today we artificially draw a direct correlation between measured age and competency. In the U.S. this is a series of laws that act as pseudo-rites of passage. At age five, a person can become enrolled in school (provided they are five by the month of August when school begins in September). At age 14, a person can be formally hired for employment. At age 15, a person can get a learner's permit to drive a car and at age 16, a person can get a driver's license. At age 17, a person can see "NC-17" (no children under 17) movies. At age 18, a person officially becomes an "adult": any legal trouble is "wiped clean", they can get married (without parental consent), join the military, buy property, vote, see "X" rated movies, be "tried as an adult" in a court of law (although some states have lowered the age limit), and of course, pay taxes. At age 21, a person can buy and consume alcohol. At age 24 or so, some insurance policies cease to cover "children" of the primary claimant. The next common age-oriented law takes effect at age 55, when retirement pensions and policies become available, and at age 65 when social security can be drawn. Where, in all this, does childhood end and adulthood begin? This question draws out the point that $\mathrm{U} . \mathrm{s}$. culture has developed the 
definition of the child and childhood on the basis of $U . S$. law, which has arbitrarily decided upon the age of 18 as the age emancipation.

There is an arbitrary sense to this modern definition that does not seem to be appropriate. Actions by younger persons are allowed or denied on the basis of age. Actions by older persons are neither allowed or denied, but considered according to standards of competency, responsibility, etc. The young engage in similar activities of the old including relationships, criminal activity, and consumer buying power. Yet, the standards are not similar. For example, it is unheard of to hear, "If you don't stop making MY sister work such long hours, I'll take her out of your employment". Yet it is very common to hear, "you're not going to expose MY child to a homosexual teacher" or "if you require students to read Catcher in the Rye, I will take MY child out of school" or "if you teach MY child about Catholicism, I will file a lawsuit". This obvious disparity denotes that parents claim ownership to their young - - a powerful assumption that is suggestive of ideology and domination within U.S. culture.

Today's U.S. culture sees children as property of their parents. It is not a culture, like some, where extended families and communities alike are educators and mentors 
(there is no one person to teach "values", etc). It is not a culture where the young as well as the old are viewed as contributing members of society. This leads to several outcomes that ultimately effect the educational system: 1) the young are left to "hang-out" until the age of 18 when they can begin making a meaningful contribution to society (primarily by voting and by getting a job); 2) schools become places for students to "hang-out"; 3) that only a child's parents know what is best for them (and therefore, the parents and no one else can dictate what their children are taught); and 4) students are not seen as knowing what they should learn, therefore they are not given the opportunity to share with teachers what they would like to learn. In summary, this issue of what and how this culture defines a "child" (that it defines the concept at all) is indicative of a dominant ideology that has important bearing on the educational system.

The Public school.

There are three main types of educational systems: private, state, and public (Smith, 1992). These three forms of education are defined by who funds and controls the schools. These forms determine who is a student of the system, and how well students learn from the system. This 
section will briefly define what private, state, and public education are in theory and then define the U.S. educational system within these terms. In doing so, another issue where ideology dominant in U.S. culture manifests will become more clear as will the implications of that ideology.

Private education is education that happens in a free and open market. So for example, some schools might be set up, funded, and run by parents while other schools might be run by church leaders and cost nothing (barring donations, etc.). Whatever the design, a private educational system allows for a great deal of diversity, but has no guarantee in terms of availability or funding. This means that the probability is very low that all children will be formally educated, however those that are formally educated are more likely to learn because they are in a system that is adapted to their circumstances. For example, many eras in western history have seen private education systems where only the wealthiest families have been formally educated.

State education is education that is both funded and controlled by the government. Curriculum requirements, teacher accreditation standards, and methods of assessing student competency are all established by government regulation. Frequently in a state system of education the guarantee for children to attend school is very high, 
however the guarantee that they will learn tends to be low. A state system educates on behalf of "state" interests. Public education is education that is funded by the government, but controlled by the public (in this sense, communities). Elements such as course requirements, who is considered a teacher and why, daily and weekly schedules, and classroom styles are determined by the "publics" to be served. This system guarantees education for children, but also provides a high probability that students will learn. Such a system has enough flexibility to it that each school would operate differently according to a specific "public's" demands and student needs.

In theory, these systems have clear advantages and disadvantages. A private educational system has the advantage of high quality education, but the disadvantage that it serves a selected few. A state educational system has the advantage of serving many, but the disadvantage that it does so poorly. Consider an observation and comparison of Athens and Sparta: Athens, had a private system of education. Western history claims its origins from the few great minds of Athens. Sparta, on the other hand, was known to have a state system of education. Western history does not lay any particular claims to sparta's citizens. History would be very different had either Athens or Sparta employed 
a public system of education -- a system which seeks to have the advantages of the other systems and minimize their disadvantages (Smith, 1992).

The educational system in the United states today is often referred to as a public education system. There is also a subsystem that is called private education -- schools that are not funded by the government. However, both names are misnomers because in both cases there is heavy government regulation. For example, the requirements for receiving a high school diploma in one state are consistent for both "public" and "private" schools. While there are variations from school to school, the basic design of the U.S. educational system is that of a state system, not a public one.

In reviewing these three educational systems, the theoretical advantages of a public system over the other two are clear, especially when there is hope to create a wellinformed citizenry. Theoretically, when a specific community wants changes to be made in the schools, two fundamental opportunities are available. First, the members of that community are free to (and expected to) create the kind of school they want -. four days a week, five days with varying schedules, start at 7 am or noon, etc. Second, the members of that community can choose from a number of 
schools as opposed to the typical system today where geographical boundaries often determine which school a student must attend.

There is a community that is trying out a public system. In Milwaukee, Wisconsin parents receive what is essentially a tuition check for a set amount. It is then up to the parents to decide how to spend that money - on a state school (fully covered by the tuition check) or on a private school (paid in part by the check and in part by the parent). So far, the system has been working effectively, and having no negative impact on either the state or the private schools.

Today, there is a commonly voiced disadvantage to the public system: the possibility that parents will seek to isolate their children in schools that only promote certain ideas and discourage (or never mention) others. This problem is at its worst in a private system, and at its best in a state system. It is important to remember, however, that poor quality, and state objectives and standardization are theoretically linked. A more public system would isolate to some degree, but provide high quality.

The primary reason for questioning the use of "public" in discussing the $0 . s$. educational system comes from the idea found in Giddens' that language carries power and 
ideology is the means of social reproduction. What comes to mind when talking about the "public educational system" verses talking about "the state educational system"?

Certainly there is a difference in response and attitude and the difference is meaningful. If people talk about a public system, then there is an underlying sense that it belongs to them, that they have some control. If people talk about a state system then there is an underlying sense that it belongs to the "government" and that they as citizens have no control. When considering parental ownership of children, the idea of "THE state" having control of "YOUR children" becomes especially noteworthy.

The idea that the U.S. public educational system is really a state system also serves as a useful example. If students were effectively taught how to think and communicate critically, then would such misnomers still exist in public rhetoric and private discussions?

Summary of Education Past and Present

This section has discussed the history and philosophy that has fostered the nature of education today. It has also examined definitions of children and public schools, issues that are central to education as they shape the attitudes of those involved with education: students, 
teachers, administrators, staff, parents, politicians and the public at large.

There is a historical trend and a philosophical trend that have shaped, respectively, U.S. educational practices and educational theories. The historical trend of educational practices has developed a system where 1deology is present in a consistent and patterned manner. This has lead to an overwhelming emphasis on career development in education as well as authoritarian style in conducting classroom instruction. The philosophical trend of educational theories has repeatedly advocated the development of a system that supports more flexible methods that promote experiential learning and learning through discovery. This philosophical trend ultimately leads to the support of democracy via a critical citizenry that is capable of critical discourse.

This section has shown how assumptions about the capability of the young have been made throughout educational history. In terms of domination and subtle assumptions, the young are assumed to naturally have a certain level of intelligence and no more. This section has also shown how the young are, by virtue of being "governed without consent", placed in the role of "non-person", as little opportunity is presented for those under the age of 
18 to engage in public discourse, participate in government, and to take personal actions. Upon a surface examination of goals and methods, the disparity becomes clear: Judging by U.S. methods of education, the way to shape and prepare youths to become critically-minded, responsible, independent, freedom-loving decision makers is to line them up in rows, instruct by mandate, treat them as property, minimize dialogue, and ignore their creative ideas. Then at the magical age of 18 , you'll have a socially responsible "adult" ready to engage in critical discourse and to participate meaningfully in government.

The recognition that the $\mathrm{J} . \mathrm{S}$. has developed more as a state system than a public one fulfills a couple of functions. First, it clarifies who maintains the bulk of educational control. Second, it serves as an explanation for why the educational system has falled to commonly teach students to think and communicate critically. It is not designed to.

All of the ideas discussed in this section illustrate where and how education has fatled generally. More importantly, these ideas have shown that the assumption of people being "unwilling to participate in government" because they are "lazy and apathetic", is unwarranted. Instead it can be seen that by isolating "children" in a 
non-critical, non-communicative, and non-participatory (in a meaningful "community" sense) environment for almost 18 years, the result will not be a person who sees themself as a citizen and a social actor that could participate meaningfully if only they were able.

\section{FUTURE EDUCATION}

If the educational system is going to fulfill the notions of competency, discovery, and ultimately democracy, then it must change. Classroom content, methods of teaching, and perspectives regarding children must change. These conclusions are not new. Advocating more communication, critical inquiry, and trial and error in the classroom is not new advocacy. This concept of education dates back 2400 years to Socrates, yet the issues remain. Education is susceptible to the modes of domination simply because individuals are susceptible to the modes of domination and of course education is created by individuals. The modes of domination encourage ideology that tends to deny the conditions that support and lead to personal action. According to Lerner, separating people from actualization leads to surplus powerlessness. This cycle is broken and otherwise prevented by critical thinking 
and dialogue. It is hoped that the schools will teach and encourage critical thinking and dialogue, but the schools are created by those who are in the cycle. This would seem to be a formidable "catch-22".

Discussions abound that center on the "problems" of education, where the so-called "solutions" are more money, better books, more control, etc. Yet, neither the problems nor their subsequent solutions get at issues of domination. Tenacity and commitment are the only means by which a healthy educational system will emerge. Specifically, the following must be openly, publicly, and critically discussed:

1. Does the United States have a public, private, or state educational system?

2. Who is a child, what does it mean to be a child, and are children property?

3. What do the various classroom styles promote, such as an authoritarian style?

4. What is the purpose of an educational system?

If these questions and discussions can happen more publicly, then the possibility is created that the educational system in the U.S. could promote critically thinking and dialogue and thus create a citizenry that is both willing and able to participate.

If these questions and discussions remain isolated and infrequent, then the educational system becomes more and 
more susceptible to notions like "Corporitization" where corporations fund and control the schools (possibly, a stronger manifestation of the "education as a training ground" ideology). The potential of this trend carrying on into the future is observed in education journals as well as the mainstream press - in articles such as $\mathrm{O.S}$. News' "Today's lesson brought to you by ..." (April 24, 1995). There have also been incidents already where the U.S. military has made the same overtures to the schools as corporations have. Additionally, more parents and students will abandon the schools for private institutions (if they can afford it) or for early employment. This will foster isolation, powerlessness, criticism of "apathy", class divisions, and decline of democratic process.

However, alternatives do exist (and are put into action) that support dialogue, critical thinking and personal action. Just recently (Oct 1994), a Time magazine cover exclaimed: "New Hope For Public Schools, in a grassroots revolt, parents and teachers are seizing control of education" (a mainstream mass media source, no less). The article focused on a "charter-school" in Michigan. The charter-school is akin to a true public school .. funded by the state and controlled by the community (public). There are individual teachers who do promote critical 
thinking and dialogue in their classrooms. These teachers often have to deal with angry parents and thus, angry administrators. There are those who engage the young in ways that communicates a concept not of "a child", but one of an independent citizen that makes meaningful contributions to the world at large. There are those who discuss education as state, not public, in an effort to stimulate public consciousness. Unfortunately these individuals are few and far between in the public sphere as public discourse is limited and isolation of individuals is common. These are the people and ideas to encourage on a larger and more public scale, if education and democracy are to mean anything at all. 
IMPLICATIONS FOR THE WORKPLACE

The previous chapters have demonstrated how the modes of domination can lead to surplus powerlessness. Michael Lerner asserts that the work environment (of all kinds) is a primary place where the conditions that foster surplus powerlessness can be found. Work and employment are a fundamental part of U.S. Iife. If a lack of actualization is so common as to limit personal actions, and to be mistaken as and to receive criticism of "apathy", then investigating the workplace becomes reasonable. This section will discuss the workplace in terms of the presence of ideology, the modes of domination in process, evidence that the conditions that support personal action are somehow restrained, and evidence that critical thinking and dialogue are limited (the means for dissipating surplus powerlessness). Finally, this section will discuss some alternative ways the organization of work can happen.

THE WORKPLACE IN THE UNITED STATES TODAY

The organization of work is socially constructed through communication. This means that all participants in a single work organization (like a company) are equal 
contributors in creating that organization fust by using language that gives it reality (i.e., "oh, I work for the XYZ Company"). Yet, how many people see themselves as the everyday creators of their place of employment? Instead, employees commonly see themselves and their colleagues as having more or less power than others according to their hierarchical position. As asserted by Giddens, all socially reproduced systems are reproduced through human communication and communication is the means by which power is expressed.

I will argue that [the relationship between communication and power-as-domination (hegemony)] is closely connected to the question of organizational interests. Simply put, power is exercised in an organization when one group is able to frame the interests (needs, concerns, world view) of other groups in terms of its own interests. In other words, the group in power can provided the frame of reference for all organizational activity. (Mumby, 1988)

According to Dennis K. Mumby, organizational hierarchy is the most common way ideology in organization is hidden. For example managers frequently have (assumed) power to dictate and delegate the goals and processes for achieving those goals to those employees "below" them. These employees are not often engaged in communication where they express what they think the goals are and how they might be achieved.

Efficiency means the best and least costly way to achieve one's ends. But the problem with this 
statement is that the concept of efficiency seems to leave open the question of whose ends, and which ends are appropriate. (Lerner, 1991)

There is little doubt that power is present in the workplace. There is also little doubt that specific goals and the means by which they are achleved exist in the workplace. Do these goals and means constitute an ideology? "Efficiency" is a term often associated with business, as are "profit", "gross and net worth", etc. Generally, the ideology of business is the ideology of capitalism. Specifically, the bulk of J.S. business carries out that ideology in a particular way.

1. To produce goods and services that make maximum profits for the owners of the corporations;

2. To keep significant decisions in the hands of the fewest number of people possible, and to ensure that the right to make these decisions is in the hands of the owners of capital and those whom they hire;

3. To ensure that their own importance as managers who are indispensable as mediators between the needs of those who own the firm and those who work for it is recognized by everyone.

The goals of production are not democratically chosen nor are they orfented to the best needs of the society; but they are in the best interests of the owners, who have disproportionate power in this society.

(Lerner, 1991)

This form of capitalist ideology and power are manifested through the modes of domination (the representation of sectional interests as universal; the 
denial or transmutation of contradictions; the naturalization of the present - reification; the identification of self within the values and goals of dominant interests - hegemony).

Certainly the organization of "work" represents itself as more universal than sectional. One only has to recall a few company slogans or mottos: "GE, We bring good things to life", "Dupont, Better living through technology", "Milk, it does a body good (brought to you by the American Dairy Council)" and so on. Each one is an attempt to associate a single product or company with a more global value. These advertisements communicate with a wide array of people, including employees.

The organization of work also engages in the denial or transmutation of contradictions. Company rhetoric discusses universal values and goals like "better living". It also discusses how employees are a vital part in making such goals happen. Yet, as Lerner points out, there is little opportunity for employees "below" the management level to offer input that is creative, innovative, and true to the vitality of achieving company goals. In fact, employees at all levels of the organizational hierarchy have some limitation as to the direction and the degree of input. There are several ways in which the organization of 
work embodies naturalization and reffication. First, speaking the words "The XYZ company is this way" fixes the system in time and space, as if it were a real and tangible structure. The ideology of business manifests in language. Second, discontentment with tasks in the workplace, the work environment, colleagues, management, deadlines, etc is extremely common (Utne Reader, Jan/Feb 1994; May/June 1995). The reaction to such discontentment is that "oh, that's natural, that's how everyone feels, welcome to the rat race". The same reaction is heard regarding the practice of business (management power, efficiency, no input elicited from employees, etc) -. "well, of course, that's how businesses are run". (An interaction that promotes venting and not personal action.) The assumption is that we are all engaged in business as usual; this is the way that work has happened throughout history and therefore on into the future.

The last mode of domination, hegemony, is also found in the organization of work. Participating in one's own domination is virtually guaranteed given the other three modes of domination. Occasionally workers hear themselves or their colleagues say, "you know, if it wasn't for us, this company wouldn't exist". However, the comment is usually said in a wistful tone of resignation. Conditions 
abound in the workplace that employees are unhappy with; this drains them, gives them health problems of all kinds (ulcers, high blood pressure, headaches, carpal-tunnel syndrome, etc.), and the feeling remains that "that's just the way it is".

We are encouraged to think that if we go along with the way things are, we will get our rewards, our salaries or paychecks, which will enable us to buy the goods and services that we need in our personal lives. We are encouraged to focus away from the human costs of this process, and to think that it is simply "unrealistic" to expect that anyone would consult us... (Lerner, 1991)

As a side note, it is important to recognize another, more general way hegemony works in conjunction with business and the world at large. Just as mass media places audiences in the role of consumer, not citizen, so does business. (And why not since mass media is after all, a business?) In other words, we are either an employee or a consumer with buying power.

The modes of domination carry an ideology that promotes the interests and goals of business at the cost of human potential, social democratic processes, and ecological cycles.

From the "lowest" employee to the "highest" executive, work in U.S. businesses takes a toll on human potential. Democracy is a process that depends upon communication of all perspectives so that the "best" policies and actions may 
be taken to maintain democracy. What is the best way to heat a home? The answer depends upon the criteria.

"Alternative" energy sources such as solar power demand little in human resources (1.e. no 16-hour days drilling ofl for limited wages) and involves little damage to ecology (some processed metal and glass as compared to strip mining, damaging salmon runs with dams, air pollution from burning oll or gas, etc.). Both the human and ecological advantages of wide-spread solar energy would have a vast effect on the world at large.

The democratic process would likely reveal alternative energy as the "best" choice. Yet, businesses have historically encouraged alternative energy projects to be set aside through lobbying the government. For example, the development of mass transportation throughout California was downsized in the early 1920's through lobbying by the auto industry. The Reagan Administration revoked the tax credit (established by the Carter Administration) given to people who installed solar heating (Greenburg \& Page, 1994). This in part, happened through lobbying by the oil industry. Clearly capitalist values are in conflict with democratic (Carnoy and Levin, 1985).

The toll the (common) organization of work in the J.s. takes on ecology is tragic. Since the dawn of the 
industrial revolution the destruction of the Earth's ecology has grown at ever increasing rates. Pollutants in the air and water ultimately damage all living organisms including one-celled creatures, reptiles, foul, fish, and mammals (including humans). Businesses turn out products in ways that fulfill their own interests but not in a fashion that is consistent with democratic values. This ever-increasing destruction impacts the very organizers of business as well as the global ecology. Drinking impure, if not poisoned, water; eating pesticide-, herbicide-, and insecticide- laden foods; breathing heavy doses of carbon-dioxide, carbonmonoxide, chlorine, and other deadly chemicals, are all products of the industrial machine that is created and run by social actors. The lack of greenery, the lack of animal life, the lack of clear skies, and the lack of clean rivers (all caused by deforestation and overdevelopment) is not only a blow to ecology but it is a blow to the human spirit. The toll the organization of work in the U.S. takes on human potential is immense. Physical, emotional, mental (or spiritual) aspects suffer due to the specific ideology discussed here. Physically, employees suffer a wide range of ills. So common are these ills that antacids, sleeping pills, pain killers, digestive aids are sold by the millions across the U.S. Again the response is to say that upset 
stomachs, insomnia, headaches, and the like are just a natural part of the human condition. Lerner's claim that stress is not natural, but an artifact of the workplace, is easily dismissed. That is, until it is realized that ulcers and heart attacks (at the age of 35 ), are not natural manifestations of stress or the human condition. The organization of work also takes a toll on people emotionally and mentally (or spiritually). Work is a part of life that is often separated from the other parts of life. The division of "public" versus "private" life is common enough (or "social" versus "professional" life). Furthermore, the organization of work cuts people off from the desire to be innovative and creative. These are forms of isolation.

We must not think of workers as victims - - but as people who in fact are doing extraordinary jobs of survival within conditions that are humanly destructive. The anger that they sometimes turn on each other at work, the pettiness and the seeming selfishness, are often the only available forms they have for expressing their frustrations at the lifedenying reality. (Lerner, 1991)

Marx's concept of "species being", Giddens' concept of the "social actor", the motivation for government according to Locke, the motivation for discovery according to Socrates, and Lerner's discussion of actualization are just a handful of places where the need for community, knowledge and self-expression are documented as human needs. While the specific ways these needs are fulfilled vary, the 
conclusion is the same: without them, humans suffer. Human suffering takes many forms, but the suffering employees experience prevents personal action as surely as if they were starving and homeless.

The physical, emotional, and mental strain that is produced by these conditions of the organization of work is detrimental to personal action. of course, the sense of resignation and helplessness do not remain in the arena of work. They are carried to home and family and to friends and social interaction. The sense of being unfulfilled turns into a sense of failure. As psychological and communication theory point out, one's self-concept shapes the nature of communication interaction. In other words, a sense of failure at work begets interactions with the family that reflects those feelings and attitudes. This cycle does not make much room for the pursuit of community, knowledge, and self-expression. Instead, the U.S. is filled with individuals who, upon returning home from work, open their genie garage door, slip anonymously into their "private" life, and announce, "I have the right to be left alone!" (Mary Ann Glendon's, Right's Talk, 1991).

This cycle also does not make room for dialogue and critical thinking. Without community, knowledge, or selfexpression, where is meaningful dialogue to occur? without 
dialogue, how is critical thinking to be encouraged?

Instead, people "leave work at the office" in order to "get away from it all". But the work remains a weight strapped to their shoulders, a weight which no longer feels unusual - they grow accustomed to its presence. If the subject of work is not open for discussion, how is the presence of ideology going to be revealed? How are simple revelations, ("we don't do that at our office, we do it this way") going to bring forth possibility. The organization of work operates under conditions that do not aid the process of Lerner's actualization nor do these conditions invite dialogue and critical thinking.

Management wants workers to talk about the details of their own immediate operations - - but they do not want workers to talk about the larger issues of the firm: how it is organized, what its products or services are and how they might be altered and improved, what happens to the profits, investment decisions, rates of production, or what the productive process is doing to the health of those who work there. (Lerner, 1991)

THE ALTERNATIVE WORK ENVIRONMENT

As it is currently organized, efficiency at work does not include the following goals:

1. To produce only goods that are necessary and thus save scarce natural resources;

2. To maximize the health and well-being of workers; 
3. To provide for meaningful and fulfilling jobs for workers ;

4. To teach workers skills in decision making and cooperative work styles;

5. To provide for the development and use of new sills by workers;

6. To use the expertise of workers in the shaping of products or services to be produced or delivered;

(Lerner, 1991)

Comments that naturalize the way business operates in the U.S. today are also accompanied by a sense that "this way" is right. Suggestions that employees are in physical or emotional pain due to the work environment are often met with denial or hostility. There seems to be a sentiment that "things are just fine the way they are, and if they ain't broke don't fix 'em." Yet, a look at alternatives reveals that improvements to the organization of work can be made that are advantageous to the employees, the owners of business, the society, and the ecology.

There have been a number of businesses that have experimented with alternative schedules, equal employee input, lateral rather than hierarchical task and management duties, etc. All of these alternatives aid the process of personal action rather than deny it. 
It's better than a long weekend, more like a minivacation. We might go skiing, or it's only a short drive to where we can hike in the mountains. In five days you can really get things done. Or just relax.

--Brigitte Dunst, German auto worker for BMW

Alternative schedules have been tried in a handful of companies including the automanufacturing companies BMW and Volkswagen (Utne Reader, May/June 1995). Employees work 30 hours a week (instead of 40 plus overtime) for the same amount of pay. These same companies have also experimented with a variation in work days where some employees work 30 hours in three days (Monday, Tuesday, and Wednesday), and others work four days (Friday through Monday). These variations allow employees to work at their own pace and at their favored times. Company owners discovered that rather than incurring a decline in profit, as would be expected, they found an increase in profit. This increase is attributed to the fact that employees are more rested. This leads to several outcomes: employees come in on time, they take fewer breaks, they feel more focused on tasks (no lack of sleep to distract them), they feel more fulfilled having more "free" time to spend with family, friends, or alone doing a variety of activities (Utne Reader, Jan/Feb 1994). This kind of flexibility would benefit the U.s. workplace and worker. 
Equal employee input and lateral task-oriented groups are two other variations in the work place that contribute to personal action. There are companies that invite employees to discuss (in great detail) their ideas, frustrations, and observations. Lateral organization rather than vertical hierarchy has also been tried by a handful of organizations. This type of organization is where several groups of employees are established, none of which has management authority over any other group. Each group concentrates on a particular task that comes together with other group projects to complete the ultimate goal. Sometimes a delegate is appointed to act as a go-between in order for communication between groups to be efficient and effective (Plunkett \& Attner, 1994). Both alternatives affect personal action. Through direct input, employees sense their ideas and concerns are real, meaningful, and that they can make a difference (alter the way something is done, for example). Lateral organization does not give the overwhelming sense that an employee is "on the bottom rung" and that they are powerless to make a difference. Instead, their input comes from an attitude that the ideas are meaningful because they, the employee, have power. (Why would one contribute ideas if they thought they had no power?) Meaningful interaction with other employees takes 
place rather than petty arguments, statements of complaint, etc. Both alternatives lead employees to experience more fulfilling work which is a process that supports personal action (Lerner, 1991).

There are also businesses that promote health and wellbeing for all employees. This includes a wide variety of meanings: cash bonuses for riding a bike to work; providing exercise and shower facilities at work; hiring in-house counselors; providing paid maternity leave for women and men; providing low-cost daycare facilities; and the list goes on (Plunkett \& Attner, 1994; Utne May/June 1995). These are all improvements on the standard organization of work, unfortunately they happen infrequently in $\mathrm{U.S.}$ businesses.

All of these alternative practices are of advantage to the employee and the employer alike. Workers feel more fulfilled and thus contribute more to the business.

However, the tougher elements are to fulfill the needs of the society and the needs of the ecology. If increased input from employees was encouraged under a full democratic perspective, then the harms of business on the ecology would eventually be voiced and more importantly be heard. The same is true about society. This would happen as there is a visionary (or radical) in every group and open dialogue 
would provide access for informed opinions. For example, would MacDonald's continue grazing cattle on the former terrain of the Amazon Rainforests if an open dialogue were to be encouraged, supported, and honestly considered? Would the American Plastles Corporation really continue producing non-recyclable plastic, if an open dialogue were to be encouraged, supported, and honestly considered? Would the Coca-Cola company have kept its factories in South Africa during the era of apartheid, if an open dialogue had been encouraged, supported, and honestly considered? In short, how far can dialogue and critical input go within the organization of work? To the point at which business evolves into what is beneficial to itself, its employees, the society, and the ecology? To the point at which it struggles in a state of economic turmoil (varying governmental regulations, employee turnover, loss of market share, etc.)? or to the point at which it dies altogether? What is most important about all of these alternative practices is that they promote work that is fulfilling for their employees. Fulfillment in this sense is based on comunication, creative input, a sense of power, a sense that ideas are meaningful and that contributions are welcome -- and most importantly that the organization is flexible in fulfilling needs. If businesses were organized in this way, 
then employees would either help create the kinds of businesses they want (which would often lead to socially and environmentally responsible businesses) or they would learn that there is more to being human than work. Either would be an improvement. 
IMPLICATIONS FOR GOVERNMENT

If an American should be reduced to occupying himself with his own affairs, at that moment half his existence would be snatched from him; he would feel it as a vast void in his life and would become incredibly unhappy.

--Alexis De Tocqueville

Today's American cultural conditions have perpetuated surplus powerlessness resulting in a lack of fulfilling human needs. In particular, the system of government only encourages certain kinds of participation and personal action such as voting or "writing your congressional representative". These limited options are actions that often feel meaningless to the U.S. citizen, i.e. "my vote can't make a difference, why bother". Thus, the Individual has lost their sense of citizenry, of being a social actor. This loss is an echo of Tocqueville's hypothesis made so many years ago.

This section will explore the modes of domination within the U.S. governmental system today. This section will also reiterate the role of dialogue and critical thinking within the system. Finally, the possibility for revitalized participation and personal action will be discussed. 
GOVERNMENT AND DOMINATION

The modes of domination are clearly present within the governmental system of the U.S. Giddens argues that there is a subtlety to these modes that enables ideology to not appear as such, but as "the way things are done" - the system appears natural. However, what is interesting is that not all the modes (in part or in full) are subtle where government is concerned. The representation of sectional interest as universal is perhaps one of the least subtle of the four modes.

Individuals in the U.S. frequently discuss the disproportionate collection of power: the wealthy have more say in government ("its who you know"), the "liberals" or the "conservatives" are argued to have more power than the other, business has more power than "ordinary" citizens, etc. Whatever the statement, and however true it may be, there is a definite sense that somebody "has more power than men.

Disproportionate power is one part of the first mode of domination -- the representation of sectional interests as universal. Another part is how political rhetoric states that power is used. Government economic policies are made that are stated to be "good for America". In other words, 
higher taxes, deregulation, or inflation are presented as "good for Americans" because they aid the economy in some way (advantages for business, for example), even if the policies are disadvantageous to the individual. Thus, the sectional interests of business, for example, are represented as good for all.

This leads directly to the second mode of domination -. the denial or transmutation of contradictions. It also raises a key issue -- the struggle between democracy and capitalism. Political rhetoric heralds the values of both democracy and capitalism. Acclaims of freedom and individual rights are matched with freedoms of the "free enterprise" system and the right to choose from a variety of products and services. The policies of both democracy and capitalism tend to contradict each other (Baradat, 1991). If power has a tendency to operate in a way that collects more power, then the motives of business (profit and competition) will undermine the process of democracy (which is supposed to disperse power). The oil industry is an excellent example. As previously discussed, democracy would seek out the "best" choice for energy production .. alternative energy sources like solar collectors. Yet, oil, gas, and destructive hydro-power (dams that harm ecology) remain the primary sources of energy. Conversely, solar and 
wind power are rarely used. How could this happen if not for the clash between democracy and capitalism?

Resignation is the primary way the third mode of domination occurs. A heavy sigh followed by "things will never change, I guess we're stuck with it", is common enough thinking. The sense that the federal decision-making machine is permanent and the sense that "somebody else" will always have the power to run it is a sense that reifies the system of government as the structure of government. In other words the buildings of washington D.C. become fixed in time and space. They become seen as formidable and unchanging. Yet the time was not so long ago when Washington D.C. was not the capital of these United states or that congressional representatives were merely ambitions citizens, not citizens with huge quantities of money and a law degree.

By sensing the inevitability of this disproportionate system, individuals act in ways that sustain it as such. This is the fourth mode of domination -- hegemony. Locke asserted that when the social contract no longer served those who made it, they could, would, and should "opt out" and redesign government. Today, citizens have a sense that the allowed actions (voting, writing letter, etc.) are meaningless, and therefore stop participating. They are 
seen as unwilling to participate in a system in which they are unable to participate. In Locke's terms this would mean that individuals are "opting out". In other words, there is a willingness to particlpate in a social contract where government does serve the needs its designers, members, and participants. The system (or social contract) changes through action. Being resigned to, and acting in ways that reinforce hegemonic conditions, does not lead to change.

\section{DIALOGUE \& CRITICAL THINRING AND GOVERNMENT}

As previous sections have shown, dialogue and critical thinking are not encouraged or promoted in vast arenas of social life. The U.S. educational system is primarily based on external transfer of facts not on the internal discovery of knowledge. Students' first encounters with formal education subject them to lecture, where students are to sit quietly and listen and where only certain questions are permitted. Students graduate from school and to the workforce where the system is much the same: someone else has power to decide what is to be done, why it is to be done, and how it is to be done. Open discussion about the "why's" and "how's" is not common in the organization of 
work. As employees escape their stressful and unfulfilling work, they slip anonymously into their homes uninterested in discussing how to change these conditions, and instead (habitually) vent about them. They turn to their newspapers, magazines, and televisions that present them with a view of the world that is unchanging in its patterns of power relationships. The fragmentation and isolation is very thorough: they are a student, an employee, a consumer, an audience member, not a social actor. Due to the modes of domination, the system of government does not tend to deviate from this pattern.

Opportunities to engage in dialogue and critical thinking are limited. Where is the town meeting held today? Where is public policy discussed and decided upon? The smaller the scope of the community, the better the opportunities are for individual participation in the dialogue. Federal policies are discussed and decided upon by congress. The opportunity to be part of this process is remote. An individual would either have to be elected as a representative or they would have to travel to Washington, D.C. and find some way to be part of the discussion. Individual participation in the making of state policies requires much of the same conditions, but geographically is slightly more feasible. There is also more probability that 
an individual could actually converse with their state representative as their constituency is smaller. As the geography becomes smaller the opportunities for and the likelihood of individual participation grow. County, city, urban districts, and nelghborhoods are aspects of the governmental system where individuals can experience more critical thought and communication, more participation, and more optimism (Glendon, 1991).

POSSIBILITIES OF THE U.S. GOVERNMENTAL SYSTEM

There are many possibilities for the future of $\mathrm{U.S}$. government and its system of operation. History tells many tales of the future envisioned by the founders of American government. These visions, it seems, were dependent on various criteria - a balance of power and citizenship, for example. There are other tales - tales of fiction -. that envision possibilities for $U . S$. government that might have or could still become realities. By examining pieces of history and pieces of fiction together, alternatives for government systems become more tangible. These alternatives are ones that hold potential for the circumstances that support rather than undermine personal action.

It is, that in a democracy, the people meet and exercise the government in person; in a republic, they 
assemble and administer it by their representatives and agents. A democracy, consequently, will be confined to a small spot. A republic may be extended over a large region.

\section{- James Madison, The Federalist (1787)}

The Federalist written by Alexander Hamilton, John Jay, and James Madison, is a commentary on the U.S. Constitution. This document, while largely in support of the constitution, is a critical discussion that presents the advantages and the disadvantages of the newly formed system of government. The formation of a republic was based on a certain sense of reasonability: governing sizeable geography (the Atlantic coast to the Mississippi) is best done through representative government. However, Madison and other constitutional supporters also defined the republic as having a limited federal government. Protection of the individual states was considered a primary task of the federal government. Over time the geography of the union has grown as have the powers of the federal government. Questions arise as to the intentions of the Founding Fathers, the design of the government, the necessity of a union of territories, etc. Recalling Thomas Jefferson's words regarding revolution ("...revolution every twenty-five years"), it would seem quite likely that the revolution is long overdue. 
Fiction is full of alternative visions of government organization. Ernest Callenbach's Ecotopia (1975) and Ecotopia Emerging (1986) portray a world where due to the desire for democracy and its outcomes, the citizens of the Northwest (from San Francisco to the Canadian border and across to the eastern borders of Washington, Oregon, and California) secede from the Union. These citizens seek to govern by self-rule in order to live in a way that is best for the society, its members, and the ecology. Gene Roddenberry's star Trek, is based on a galactic "federation" where any planet may belong to the federation so long as they agree to some basic tenets. The planets retain their autonomy, their culture, and their systems so long as they comply with the basic federation guidelines. The visionary genre of fiction is often overlooked, and instead is treated as trivial, insignificant, or just a nice story. Yet, consider what secession by the South in 1861 would have meant in terms of these stories. It is possible that a federation of states and not a union of states, would have emerged. The Bill of Rights may have served as the basic laws of the federation and over time anyone throughout the entire world could become a member of the federation. The possibilities that would follow are immense. However, the federal government chose a path in 1861 that has led to more 
power for the federal government, less power for the state government and therefore a declining sense of autonomy for the citizens of these Onited states (Hofstadter, 1958).

Callenbach's Ecotopia Bmerging, demonstrates how individuals in today's culture could experience more fulfillment. The portrayal and demonstration is realistic. Individuals battle the dominant power lobby to implement solar energy, they battle the auto industry to turn cities into mass transit areas only, they battle state regulations to create public schools (not private or state institutions), they battle political elites for citizen self-government, and ultimately they battle the federal government for secession. The perceptions created out of domination would tend to disregard such changes as works of fiction and idealism.

Jefferson's belief in the frequency and necessity of revolution and Locke's belief in the reconstruction of the social contract are possibilities. Smaller government "of the people" that is democratic government is a system where citizens experience dialogue and critical thinking. Furthermore, it is a system where personal actions are plentiful and individual actualization is possible. If perceptions of "apathy" and "laziness" are to fall to the wayside and if government by consent is to be realized, then 
the system must change. The democracy of Ancient Greece evolved (quite naturally) into a republic. The republic of Greece became the Roman Empire. If the modes of domination continue to carry ideology unabated with regard to U.S. government, then 1 t is possible that cltizens of the U.s. Republic will find themselves subjects of the U.S. Empire (Willams, 1980). (Whether it is actually called an empire remains to be seen.)

As with education, those that do see themselves as social actors perhaps should focus their energy on the larger scope (instead of who has more power: the Democrats or the Republicans?) Perhaps, targeting the purposes, principles, and practices of the governmental system is more likely to create meaningful change -- change that maintains a balance between extreme law and extreme chaos - than targeting individual, isolated policies. Regardless of the approach, the need and urgency are clear. 
CHAPTER V

THESIS SUMMARY

This thesis has examined the concept relationships of dialogue, critical thinking, and the barriers against them through the exemplary works of Socrates, Locke, Marx, Giddens, and Lerner. This thesis has provided a synthesis of these examples centered around the choosen concepts. This thesis has also examined several arenas of U.S. life and culture: mass media, education, work; and government. Through this examination it has become clear where and how ideology subverts individual interests. It has also become clear that dialogue and critical thinking are not common in these significant arenas. The question remains, "what is to be done with all this information?" The final chapter of this thesis offers two final observations followed by a request for action and application by you, the reader.

An important discovery and observation to take from this research is that process has meaning. Often, we strive for goals: Who won the election? Can I get a job as a result of my education, How much profit did the company make this year?, etc. But dominant ideology in the 0.s. establishes goals without thoughtful process. The processing of our assumptions leads to many places: discovery (Socrates), 
sharing (Locke), "laying bare" (Marx), penetrating (Giddens), or dissipation (Lerner). If barriers are to be penetrated and if personal action is to occur, then process must be paid attention.

This research has proposed that dialogue and critical thinking lead to personal action. Yet, we must observe that it is not certain that personal action will result in democratic processes across the cultural spectrum. Nor is it certain that democratic processes will create socially responsible governmental policies, businesses, educational systems, or journalism. What is certain, however, is that there is an obvious and compelling need to try.

As we step forward into the new millenium where technology holds the promise of the "global community" as well as the threat of new breeds of oppression, each one of us must make a commitment to our vision of the future we desire. We each have values and Ideals we would like to become realized. There are three steps we must take for this to happen. First, we must learn if these values and ideals are ones we want for ourselves or if they are ones that have been handed to us unwittingly through the pattern that makes ideology dominant. Do we choose to live in an isolated nuclear family for a personally meaningful reason or is it something that we've done out of habit? second, we must discover the implications of our ideals and our values 
- to what do they lead and whom do they effect? Too often, decisions, policies, and actions are taken in common daily experience that have unintended consequences. Did the rebels of the Boston Tea Party ever imagine that by objecting to the British tea tax we would ultimately become a nation of coffee drinkers? Finally, we must take actions that summon our visions of the future. We cannot expect that without our conscious, proactive efforts the future that unfolds will be to our liking. We must recognize that "doing by example" is the way in which we go forth from the present into the future to create a world we want. These three steps are rooted in our willingness as well as our ability to seek dialogue and critical thinking in order to penetrate the pattern of domination and to engage personal action. The changes we want many appear monolithic and our efforts microscopic, but we must continue all the same if we are to do more than just survive.

We must apply these three steps to all areas of our lives. We must examine the information we take in from mass media. A simple comparison of two news sources (The Oregonian and the New York Times, for example) would aid our understanding of how information is framed and how the framing shapes our ideas. We should look critically at the juxtaposition of certain programs and commercials. We should make fun of certain programs and commercials. We 
must not suspend our disbelief or tune out the world of mass mediated images, because they will affect us most when we are not paying attention. We must ask ourselves are we citizens or consumers or something else entirely?

We must examine our attitudes about the educational system, even if we are not part of it, if for no other reason than all children are important for society today as well as for the society of tomorrow. Do we readily accept a state system of education that may not provide the best teachers, materials, or goals? How do we interact with children - do we think of them as sentient, capable humans or do we pat them on the head and exclaim, "she's so darling ! "

For many of us the our place of work is central to our life and it is for this reason we must apply these three steps of inquiry to our work. Does our job or career provide enough time for creative endeavors? Does it leave us irritated, overworked, and reactionary? Too often, we carry these feelings into our homes and into our social interactions. If we find our relationships failing, we should first look at our place of work and ask, "what is going on herep" We must attempt to create a place of work that is meaningful to us in someway and if possible, to urge employers to seek schedules and organization that is flexible and open to suggestion (it will increase 
productivity!)

Finally we must realize that participation in government, politics, and social issues does not require money, a law degree, or spectalized understanding. What it does require is patient critical inquiry and vocal and proactive efforts. We must consider the potential of voting (or not voting), of writing letters, of making phone calls, of standing on a street corner with a sign, of giving speeches and urging others to act.

These arenas -- mass media, education, the workplace, and government - - are not separate and distinct. They are in fact descriptions of the same system: social interaction. If we our dissatisfied with the world, we must know that yes, some people have more power and leverage than us and yes, roadblocks to change exist. We must also know that the words we use to describe the world shape the world and the actions we take in the world create our surroundings. We are not to blame for the world we were borne into or for being susceptible to the systemic and overwhelming nature of ideological domination. We are responsible for examining the world we were born into and for penetrating the pattern of ideological domination. Once armed with the knowledge our examination brings forth, we are responsible for use our words and our actions with forethought and conscious effort. We are responsible for mustering our energy, our willpower, 
and our tenacity, when we find ourselves thinking, "oh, fust this once, no one will care". We must guard ourselves against slipping into a pattern of behavior that is not of our own design. These are the thoughts that I implore each and every one of us to carry with us everyday. I believe that, with time, our habits will be conscious ones and our surroundings will be more fulfilling every day. Remember, every one of us "makes history" - - what do you want history to look like? With this question in mind, I will leave you with the words of an individual who changed an entire country simply with his dedication to his vision and with his belief in "doing by example":

Whatever you do may seem insignificant, but it is most important you it.

- The Mahatma, Mohandas K. Gandhi 


\section{REFERENCES CITED}

Altheide, D.L. (1985). Media Power, Beverly Hills, California: Sage Publications, Inc.

Anderson, J.A. (1987). Communication Research: Issues and Methods. New York: McGraw-Hill Publishers.

Bennett, S.E. (1986). Apathy in America: 1960-1984, Causes $\&$ Consequences of Citizen Political Indifference. Dobbs Ferry, New York: Transnational Publishers, Inc.

Biegel, D.E. (1984). Help Seeking and Receiving in Urban Ethnic Neighboorhoods: Strategies for Empowerment, (pp.119-144). In Rappaport, J. \& Hess, R. (Eds.), New York: the Haworth Press. Studies in Empowerment.

Boggs, C. (1980). Gramsci's Marxism, Southampton, Great Britian: The Camelot Press Limited.

Bohman, J.F. (1990). Communication, Ideology, and Democratic Theory. American Political Science Review, 84, 93-109.

Bosk, C.I. (1988). The Rise and Fall of Social Problems: A Public Arenas Model. American Journal of Sociology, 94, 53-78.

Chaffee, J. (1994). Teaching for Critical Thinking. Educational Vision, pp. 24-25.

Carnoy, M. (1984). The state \& Political Theory. New Jersey: Princeton University Press.

Carnoy, M. \& Levin, H.M. (1985). Schooling and Work in the Democratic state. California: Stanford University Press.

Dahlgren, P. (1981). TV News and the Suppression of Reflexivity (pp. 101-113). In E. Katz \& T. Szecsko's Mass Media and Social Change. Beverly Hills, California: Sage Publications, Inc.

Dearborn, J. (1991). How to Prevent Pesticide Pollution. Beaverton, Oregon: DHJKI Publishing Co.

Dewey, J. (1966). Democracy and Education, New York: Free Press. (Original work published 1916) 
Dewey, J. (1938). Experience \& Education. Kappa Delta P1.

Dewey, J. (1927). The Public \& its Problems. Chicago: Henry Holt \& Company.

Dye, T.R. \& Zeigler, H. (1993). The Irony of Democracy: An Uncommon Introduction to American Politics. Belmont, California: Wadsworth Publishing Co.

Entman, R.M. (1989). Democracy without Citizens: Media and the Decay of American Politics. New York: Oxford University Press.

Entman, R.M. (1989). How the Media Affect What People Think: An Information Processing Approach. Journal of Politics, 51, 347-370.

Fineman, H. (Feb. 26, 1995). Digital Democracy. The oregonian. Forum, Sec. B.

Flanigan, W.H. \& Zingale, N.H. (1987). Political Behavior of the American Electorate. Boston: Allyn and Bacon, Inc.

Flew, A. (1984). A Dictionary of Philosophy. New York: st. Martin's Press.

Freeman, E. \& Appel, D. (1974). The Wisdom and Ideas of Plato. Greenwich, Conneticut: Fawcett Publications, Inc.

Frey, L.R., et. al. (1991). Investigating Communication: An Introduction to Research Methods. New Jersey: Prentice Hall.

Furth, H.G. (1969). Piaget and Knowledge: Theoretical Foundations. New Jersey: Prentice Hall, Inc.

Gentles, F. \& Steinfield, M. (1974). Hangups From Way Back:Historical Myths and Canons. San Francisco, California: Canfiled Press.

Giddens, A. (1979). Central Problems in Social Theory: Action, structure and Contradiction in Social Analysis. Reprint, 1986. Los Angeles, California: University of California Press. 
Gitlin, T. (1980). The Whole World is Watching: The Mass Media and the Making and Unmaking of the New Left. Berkeley, California: University of California Press.

Glaser, B.G. \& Strauss, A.L. (1967). The Discovery of Grounded Theory: strategies for qualitative research. New York: Aldine de Gruyter, Inc.

Glasser, I. \& Adelman, B. (1991). Visions of Liberty. New York: Arcade Publishing, Inc.

Glendon, M.A. (1991). Rights Talk: The Impoverishment of Political Discourse. New York: The Free Press.

Golden, J.L., Goodwin. B.F., \& Coleman, W.E., The Rhetoric of Western Thought. Iowa: Kendall/Hunt Publishing Company.

Golding, P. (1981). The Missing Dimensions: News Media and the Management of Social Change (pp. 63-81). In E. Katz \& T. Szecsko's Mass Media and Social Change. Beverly Hills California: Sage Publications, Inc.

Greenberg, E.S. \& Page, B.I. (1995). The Struggle for Democracy. New York: HarperCollins College Publishers.

Hamilton, A., Jay. J., \& Madison, J. (1787). The Federalist. (Reprinted 1899 by The Kinckerbocker Press, New York).

Hill, B. (1993). The Value of Competitive Debate as a Vehicle for Promoting Development of Critical Thinking Ability. Ceda Yearkbook, 14, pp. 1-22.

Hirsch, E.D. (1987). Cultural Literacy: What Every American Needs to Know. Boston: Houghton Mifflin Company.

Hofstadter, R. (1958). Great Issues in American History: From the Revolution to the Cival War, 1765-1865). New York: Vintage Books.

Huspek, M. \& Kendall, K.E. (1991). On Withholding Polictical Voice: an Analysis of the Political Vocabulary of a "Nonpolitical" Speech Community. The Quarterly Journal of Speech, 77, pp. 1-19. 
Kallick, D. (1989). The Philospher as Teacher. The Speakerly Teacher: Socrates and writing. Metaphilosopy, 20, pp. 341-346.

Keiffer, C.H. (1984) Citizen Empowerment: A Developmental Perspective, (pp. 9-36). In Rappaport, J. \& Hess, R. (Eds.), studies in Empowerment. New York: the Haworth Press.

Lazere, D. (1987). American Media and Mass Culture: Left Perspectives. Berkeley: University of California Press.

Lerner, M. (1991). Surplus Powerlessness: The psychodynamics of everyday life and the psychology of individual and social transformation. New Jersey and London: Humanities Press International, Inc.

Marx, K. (1867). Das Kapital.

Marx, K. (1848). The Communist Manifesto.

Maslow, A.H. (1968). Toward a Psychology of Being. New York: Van Nostrand Reinhold Company Inc.

McCormack, T. (1986). Reflections on the Lost Vision of Communication Theory (pp.34-42). In Ball-Rokeach, S.J. \& Cantor, M.G. (Eds.), Media, Audience and Social structure. Beverly Hills, California: Sage Publications, Inc.

Meyrowitz, J. (1985). No Sense of Place. New York: Oxford University Press.

Mumby, D.K. (1988). Communication and Power in Organizations: Discourse, Ideology and Domination. Norwood, New Jersey: Ablex Publishing Corporation.

Mumby, D.K. (1989). Ideology \& the Social Construction of Meaning: A Communication Perspective. Communication Quarterly, 37, pp. 291-304.

Noelle-Neumann, E. (1984). The Spiral of Silence. Chicago and London: The University of Chicago Press.

Ollman, B. (1993). Dialectical Investigations. New York and London: Routledge. 
O'Sullivan, M.J., Waugh, N. \& Espeland, W. (1984) The Fort McDowell Yavapal: From Pawns to Powerbrokers, (pp. 73-98). In Rappaport, J. \& Hess, R. (Eds.), studies in Empowerment. New York: the Haworth Press.

Page, B.I., Shapiro, R.Y., \& Dempsey, G.R. (1987) What moves Public opinion? American Political science Review, 81, pp. 23-43.

Parenti, M. (1988). Democracy for the Few. New York: st. Martin's Press, Inc.

Paul, R.W. (1990) , Critical Thinking: What Every Person Needs to Survive in a Rapidly Changing world. Rohnert Park, California: Center for Critical Thinking and Moral Critique, Sonoma state University.

Piaget. J. (1968). Six Psychological studies, New York: Random House, Inc.

Plunkett, W.R., \& Attner, R.F. (1994). Introduction to Management. Belmont, CA: Wadsworth Publishing, Inc.

Postman, N. (1982). The Disappearance of Childhood. New York: Vintage Books.

Rappaport, J. (1984) Studies in Empowerment:

Introduction to the Issue, (pp.1-8). In Rappaport, $J$. \& Hess, R. (Eds.), studies in Empowerment. New York: the Haworth Press.

Roberts, D.F. \& Maccoby, N. (1985). In Aronson, E. and Lindzey, G., eds., The Handbook of Social Psychology, Vol. II. New York: Random House.

Rucinski, D. (1992). Personalized Bias in News: The Potency of the Particular?. Communication Research, 19, pp. 91-108.

Singer, E. (1990). A Question of Accuracy: How Journalists and Scientists Report Research on Hazards. Journal of Communication, 40, pp.??

Taylor, A.E. (1953). Socrates: the Man and His Thought. New York: Anchor Books.

Time Magazine, (Jan 23. 1995). Is Rush Limbaugh Good for America? (cover). 
Time Magazine. (Jan. 9, 1995). King of the Hill.

Exclusive: How Newt Gingrich plans to pull off his revolution (cover).

Time Magazine. (Oct. 31, 1994). New Hope For Public

Schools. In a grass-roots revolt, parents and teachers are seizing control of education (cover).

U.S. News, (April 24, 1995). Today's Iesson brought to you by... (cover).

Utne Reader. (May/June 1995). After Work (cover story).

Utne Reader. (January/February 1994). Too Busy? (cover story).

Wheelwright, P. (1954). The Way of Philosophy. New York: the Odyssey Press.

Whorf, B.L. (1956). Language, Thought, and Reality. New York: John Wiley.

Williams, A.พ. (1980). Empire as a Way of Life, New York: Oxford University Press.

Wired Magazine. (Feb. 1995). The Cable Slayer BellAltantic CEO Ray Smith Explains Why Cable Is Dead (cover). 